ARTICLE

https://doi.org/10.1038/s41467-018-08136-3

\title{
Non defect-stabilized thermally stable single-atom catalyst
}

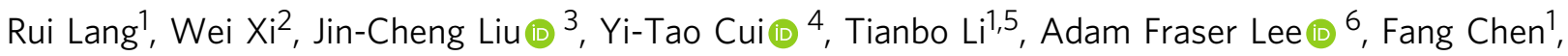

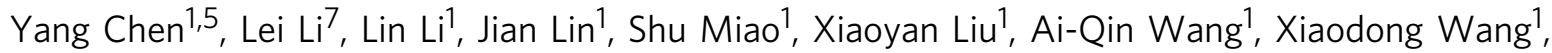 \\ Jun Luo ${ }^{2}$, Botao Qiao (1) ${ }^{1,8}$, Jun $\mathrm{Li}^{3,9} \&$ Tao Zhang ${ }^{1}$
}

Surface-supported isolated atoms in single-atom catalysts (SACs) are usually stabilized by diverse defects. The fabrication of high-metal-loading and thermally stable SACs remains a formidable challenge due to the difficulty of creating high densities of underpinning stable defects. Here we report that isolated Pt atoms can be stabilized through a strong covalent metal-support interaction (CMSI) that is not associated with support defects, yielding a highloading and thermally stable SAC by trapping either the already deposited Pt atoms or the $\mathrm{PtO}_{2}$ units vaporized from nanoparticles during high-temperature calcination. Experimental and computational modeling studies reveal that iron oxide reducibility is crucial to anchor isolated Pt atoms. The resulting high concentrations of single atoms enable specific activities far exceeding those of conventional nanoparticle catalysts. This non defect-stabilization strategy can be extended to non-reducible supports by simply doping with iron oxide, thus paving a new way for constructing high-loading SACs for diverse industrially important catalytic reactions.

\footnotetext{
${ }^{1}$ State Key Laboratory of Catalysis, Dalian Institute of Chemical Physics, Chinese Academy of Sciences, Dalian 116023, China. ${ }^{2}$ Center for Electron Microscopy and Tianjin Key Lab of Advanced Functional Porous Materials, Institute for New Energy Materials, School of Materials, Tianjin University of Technology, Tianjin 300384, China. ${ }^{3}$ Department of Chemistry \& Key Laboratory of Organic Optoelectronics and Molecular Engineering of the Ministry of Education, Tsinghua University, Beijing 100084, China. ${ }^{4}$ Synchrotron Radiation Laboratory, Laser and Synchrotron Research Center (LASOR), The Institute for Solid State Physics, The University of Tokyo, 1-490-2 Kouto, Shingu-cho Tatsuno, Hyogo 679-5165, Japan. ${ }^{5}$ University of Chinese Academy of Sciences, Beijing 100049, China. ${ }^{6}$ School of Science, Royal Melbourne Institute of Technology University, Melbourne VIC3001, Australia. ${ }^{7}$ Synchrotron Radiation Nanotechnology Center, University of Hyogo, 1-490-2 Kouto, Shingu-cho Tatsuno, Hyogo 679-5165, Japan. ${ }^{8}$ Dalian National Laboratory for Clean Energy, Dalian 116023, China. ${ }^{9}$ Department of Chemistry, Southern University of Science and Technology, Shenzhen 518055, China. These authors contributed equally: Rui Lang, Wei Xi and Jin-Cheng Liu. Correspondence and requests for materials should be addressed to J.L. (email: jluo@tjut.edu.cn) or to B.Q. (email: bqiao@dicp.ac.cn) or to J.L. (email: junli@tsinghua.edu.cn)
} 
eterogeneous catalysis is pivotal to the modern chemical industry ${ }^{1}$, with many heterogeneous catalysts comprising transition metals deposited over a solid support phase ${ }^{2}$. A recent evolution in this field is the dispersion of isolated, individual metal atoms over the support to form single-atom catalysts $(\mathrm{SACs})^{3}$. Such SACs have attracted considerable attention as a new frontier in heterogeneous catalysis ${ }^{4,5}$, affording enhanced precious metal thrifting ${ }^{6}$ and atom economy ${ }^{7-9}$, improved active site homogeneity ${ }^{10-12}$, and the ability to tune the metal-support interface with unprecedented control ${ }^{13-16}$, resulting in superior catalytic activity ${ }^{17-20}$ and/or high selectivity ${ }^{21-23}$. A diverse range of supports are known to stabilize isolated metal atoms, notably through pinning at electronic and/or structural defects associated with coordinatively unsaturated sites (CUS) by experimental and density functional theory (DFT) studies (Supplementary Appendices I and II ${ }^{24-33}$. The concentration of atomically-dispersed metal atoms, and their stability, are therefore intrinsically linked to the density and stability of defects as described in recent reviews (Supplementary Appendix III) ${ }^{34,35}$. However, it is extremely difficult to create a high density of thermally stable support defects $^{36}$, and hence the fabrication of high metal loading SACs remains currently a formidable challenge.

Here we report the discovery that single metal atoms can be stabilized through a strong covalent metal-support interaction (CMSI) that is not associated with surface defects, enabling the genesis of high concentrations of thermally stable single atoms, even on low-surface-area materials. In situ genesis of ferric oxide supported Pt SAC from Pt nanoparticles (NPs) is verified in methane combustion reaction, one of the primary means of human energy production and important for mitigating environmental challenge associated with $\mathrm{CH}_{4}$ emission. Experimental and DFT studies demonstrate that metal oxide reducibility dictates the ability of a support to anchor isolated Pt atoms: $\alpha-\mathrm{Fe}_{2} \mathrm{O}_{3}$ favors atomically dispersed $\mathrm{Pt}$, whereas $\mathrm{Al}_{2} \mathrm{O}_{3}$ favors NP sintering. However, the non defect-stabilization strategy can be extended to non-reducible oxide by simply doping with iron oxide. This finding provides a promising method to fabricate high-metal-loading SACs with excellent thermal stability.

\section{Results}

Co-precipitation prepared thermally stable $\mathrm{Pt}_{\mathbf{1}} / \mathrm{FeO}_{\boldsymbol{x}}$. A $1.8 \mathrm{wt} \%$ $\mathrm{Pt} / \mathrm{FeO}_{x}$ catalyst was first prepared by co-precipitation (the synthesis details are in the Methods section), denoted as $\mathrm{Pt}_{1} /$ $\mathrm{FeO}_{x}$, and subsequently calcined at $800^{\circ} \mathrm{C}$ in air for $5 \mathrm{~h}$, denoted as $\mathrm{Pt}_{1} / \mathrm{FeO}_{x}-\mathrm{C} 800$. Aberration-corrected high-angle annular darkfield scanning transmission electron microscopy (AC-HAADFSTEM) with sub-angstrom resolution was used to compare the nature of platinum species between these two materials. In neither case were Pt nanoclusters or NPs observed (Supplementary Figures 1 and 2). $\mathrm{Pt}_{1} / \mathrm{FeO}_{x}$ comprised isolated $\mathrm{Pt}$ atoms dispersed on the $\mathrm{FeO}_{x}$ support with some Pt atoms exactly aligned with the $\mathrm{Fe}$ atomic columns (Fig. 1a-b). Corresponding $\mathrm{CO}$ diffuse reflectance infrared Fourier transform spectroscopy (DRIFTS) of $\mathrm{Pt}_{1} / \mathrm{FeO}_{x}$ (Supplementary Figure 1c) shows a coverageindependent band at $\sim 2089 \mathrm{~cm}^{-1}$ and the absence of bridged adsorption of CO band $\left(\sim 1860 \mathrm{~cm}^{-1}\right)$, which is consistent with the CO linearly bound to isolated $\mathrm{Pt}$ atoms ${ }^{3}$. Note that our CO infrared bands are broader than those recently reported by Christopher and co-workers ${ }^{37}$. However, this is unsurprising because in their work ultra-dilute $(0.05 \mathrm{wt} \%)$ Pt loadings were used to immobilize only one $\mathrm{Pt}$ atom per $5 \mathrm{~nm}$ monodispersed anatase nanocrystal. Such low loadings favor the population of only the most reactive titania surface sites, and hence a homogeneous local environment. Platinum sintering was not observed following $800^{\circ} \mathrm{C}$ calcination by either AC-HAADF-STEM
(Fig. 1c-d and Supplementary Figure 2a-b), or powder X-ray diffraction (Supplementary Figure $2 \mathrm{c}$ ) analysis of the $\mathrm{Pt}_{1} / \mathrm{FeO}_{x^{-}}$ C800 sample. X-ray absorption spectroscopy (XAS) studies provide further evidence for the complete dispersion of $\mathrm{Pt}$ atoms. Figure 1e presents the Fourier transform radial distribution functions of $k^{3}$-weight extended X-ray absorption fine structure (EXAFS) spectra for $\mathrm{Pt}_{1} / \mathrm{FeO}_{x}$ before and after calcination. Similar to our previous reports ${ }^{3}$, no $\mathrm{Pt}-\mathrm{Pt}$ bond contribution was found. This observation is in marked contrast to the significant sintering typically noted for small metal species/atoms sintered to calcination at elevated temperature ${ }^{38,39}$, and indicates a very strong interaction between $\mathrm{Pt}$ atoms and $\mathrm{Fe}_{2} \mathrm{O}_{3}$ that inhibits migration and sintering of the former. $\mathrm{X}$-ray absorption near edge structure (XANES) measurements confirmed that the chemical state of $\mathrm{Pt}$ atoms before and after calcination resembled that $\mathrm{PtO}_{2}$ with tetravalent $\mathrm{Pt}(\mathrm{IV})$ (Supplementary Figure 2d) rather than metallic platinum with zerovalent $\operatorname{Pt}(0)^{3}$.

Pt NP-generated high loading Pt SACs on $\mathrm{Fe}_{2} \mathrm{O}_{3}$ support. $\mathrm{Pt}$ NPs are known to liberate mobile $\mathrm{PtO}_{2}$ species at elevated temperature under an oxidizing atmosphere ${ }^{40}$, which may be subsequently trapped by either larger Pt NPs (Ostwald ripening) or unique oxide sites or crystalline facets resulting in metal disper$\operatorname{sion}^{41-45}$. In the present case, wherein a strong interaction between Pt atoms and the $\mathrm{Fe}_{2} \mathrm{O}_{3}$ support is apparent, we anticipate that $\mathrm{Pt}$ atoms vaporized from a NP could be trapped and stabilized by the $\mathrm{Fe}_{2} \mathrm{O}_{3}$ surface. To test this hypothesis, preformed colloidal Pt NPs were supported on $\mathrm{Fe}_{2} \mathrm{O}_{3}$ at a $0.3 \mathrm{wt} \%$ loading and the ethylene glycol stabilizer was removed by a $500{ }^{\circ} \mathrm{C}$ calcination (denoted as $0.3 \mathrm{Pt} / \mathrm{Fe}_{2} \mathrm{O}_{3}-\mathrm{NP}$ ), prior to various high-temperature calcination treatments. HAADF-STEM imaging revealed the presence of 2-3 nm diameter Pt NPs (Supplementary Figure $3 \mathrm{a}-\mathrm{b})$. In contrast to $\mathrm{Pt}_{1} / \mathrm{FeO}_{x}$ materials, $\mathrm{CO}$ DRIFTS of $0.3 \mathrm{Pt} / \mathrm{Fe}_{2} \mathrm{O}_{3}-\mathrm{NP}$ exhibited both bridging $\left(1839 \mathrm{~cm}^{-1}\right)$ and coverage dependent linear bound CO $\left(2072-2064 \mathrm{~cm}^{-1}\right)$ (Supplementary Figure 3c), which is consistent with extended arrays of $\mathrm{Pt}$ atoms. Higher temperature calcination $\left(800^{\circ} \mathrm{C}, 5 \mathrm{~h}\right)$ resulted in the complete disappearance of these Pt NPs (denoted as $0.3 \mathrm{Pt} / \mathrm{Fe}_{2} \mathrm{O}_{3}-\mathrm{C} 800$, Supplementary Figure $4 \mathrm{a}$ ), and concomitant formation of a very high density of isolated Pt atoms (Supplementary Figure 4b). Fig. 2 presents the Fourier transform radial distribution function of the $\mathrm{Pt} \mathrm{L}_{\mathrm{III}}$-edge $k^{3}$-weighted EXAFS spectrum of $0.3 \mathrm{Pt} / \mathrm{Fe}_{2} \mathrm{O}_{3}-\mathrm{C} 800$, alongside reference distribution functions for $\mathrm{Pt}$ foil and $\mathrm{PtO}_{2}$ (corresponding EXAFS spectra and fits appear in Supplementary Figure 5 and Supplementary Table 1). Two prominent scattering distances are observed for $0.3 \mathrm{Pt} / \mathrm{Fe}_{2} \mathrm{O}_{3}-\mathrm{C} 800$ at $\sim 1.7 \AA$ and $2.7 \AA$ attributed to $\mathrm{Pt}-\mathrm{O}$ and $\mathrm{Pt}-\mathrm{Fe}$ contributions ${ }^{3,27}$, respectively, confirming only the sole presence of atomically-dispersed Pt atomic species.

Note that some $\mathrm{Pt}$ NPs remained visible by electron microscopy after a lower temperature $\left(600^{\circ} \mathrm{C}\right)$ calcination, albeit more loosely coordinated to the underlying support (Supplementary Figure 4c). An oxidizing atmosphere was critical to observe this high-temperature dispersion; annealing $0.3 \mathrm{Pt} / \mathrm{Fe}_{2} \mathrm{O}_{3}-\mathrm{NP}$ under Ar at $800^{\circ} \mathrm{C}$ promoted Pt aggregation into larger $3-5 \mathrm{~nm}$ particles (Supplementary Figure 4d). This observation strongly implicates oxidized Pt species in Pt NP dispersion (Fig. 3), and indeed X-ray photoelectron spectra (XPS) (Supplementary Figure 6c) provide direct evidence for high-valent (near + IV) $\mathrm{Pt}$ in the $0.3 \mathrm{Pt} / \mathrm{Fe}_{2} \mathrm{O}_{3}-\mathrm{C} 800$ catalyst. This is quite different from those divalent $(+\mathrm{II}) \mathrm{Pt}$ ions dominating on $\mathrm{CeO}_{2}$ support after high-temperature calciantion ${ }^{46,47}$, and hence further evidences a stronger $\mathrm{Pt}-\mathrm{Fe}_{2} \mathrm{O}_{3}$ interaction that partially arises from covalent bonding interaction ${ }^{48,49}$. Three requirements emerge for the successful conversion of Pt NPs into atomically dispersed Pt: a 

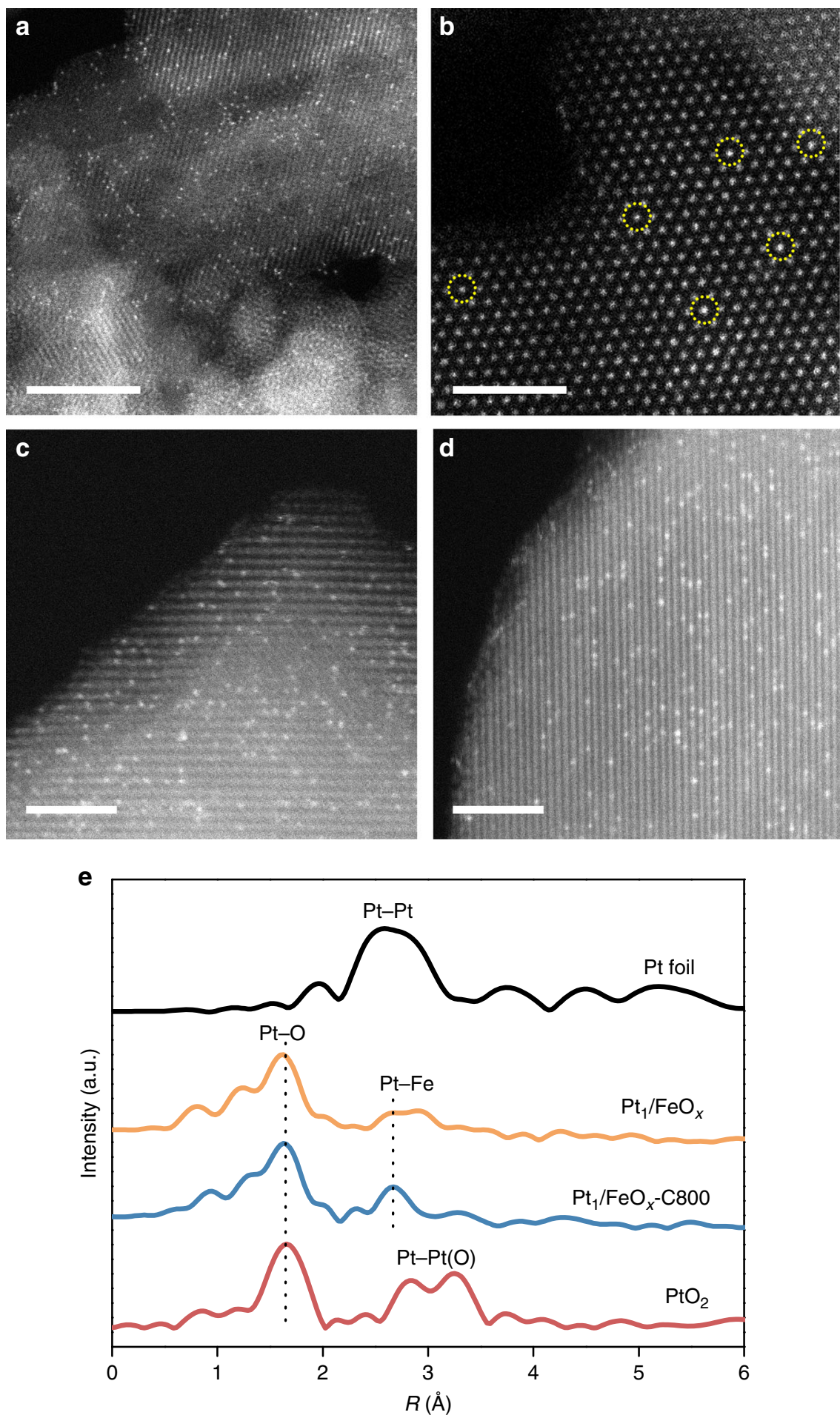

Fig. 1 Structure of $\mathrm{Pt}_{1} / \mathrm{FeO}_{x}$. a, b AC-HAADF-STEM images of $\mathrm{Pt}_{1} / \mathrm{FeO}_{x}$, and $\mathbf{c}$, $\mathbf{d} \mathrm{Pt}_{1} / \mathrm{FeO}_{x}-\mathrm{C} 800$, highlighting atomically dispersed $\mathrm{Pt}$ (circled in $\mathbf{b}$ ). $5 \mathrm{~nm}$ scale bar for panel $\mathbf{a}$, and $2 \mathrm{~nm}$ scale bars for $\mathbf{b}, \mathbf{c}$, d. e Fourier transform radial distribution function of the Pt $L_{\| 11}$-edge $k^{3}$-weighted EXAFS spectra of Pt ${ }_{1} /$ $\mathrm{FeO}_{x}$ before and after calcination in comparison with $\mathrm{PtO}_{2}$ and $\mathrm{Pt}$ foil

high temperature to promote Pt mobility; the presence of molecular $\mathrm{O}_{2}$ to partially oxidize the surface of Pt NPs, thereby enabling vaporization of (mobile) $\mathrm{PtO}_{2}$; and a strong interaction between support and surface Pt atoms. Consequently, highly stable static single atoms on heterogeneous surface can be fabricated ${ }^{50}$.

The first condition is met for $\mathrm{H}_{2} \mathrm{PtCl}_{6}$ functionalized $\alpha-\mathrm{Al}_{2} \mathrm{O}_{3}$ (Supplementary Figure $7 \mathrm{a}-\mathrm{b}$ ) subjected to the same hightemperature processing. However, in this case the weak metal- support interaction favors Ostwald ripening and the growth of large $(10 \sim 50 \mathrm{~nm})$ Pt particles (Supplementary Figure $7 \mathrm{c}-\mathrm{d}$ ) over their dispersion, as previously reported ${ }^{42}$. Since the particle size in the fresh sample ranges from 2-20 nm (Supplementary Figure 7b), and the dynamics of Pt NP dispersion into Pt atoms are related to particle size ${ }^{51}$, a control experiment was further performed, in which 2-3 nm Pt NPs were deposited over $\mathrm{Al}_{2} \mathrm{O}_{3}$ (Supplementary Figure $7 \mathrm{e}-\mathrm{f}$ ). Sintering was again observed after heat treatment (Supplementary Figure $7 \mathrm{~g}-\mathrm{h}$ ), confirming a weak interaction 
between alumina and Pt species. We note that dispersion of $<1 \mathrm{~nm}$ Pt NPs was recently reported over MCM-22 ${ }^{51}$, which may reflect restricted migration of $\mathrm{Pt}$ species through the microporous zeolite network.

Having identified conditions under which Pt NPs can be dispersed over an $\mathrm{Fe}_{2} \mathrm{O}_{3}$ surface, we explored the effect of $\mathrm{Pt}$ loading with a view to maximizing the density of isolated atoms achievable, and thereby compensate for the extremely low surface area (only $5-10 \mathrm{~m}^{2} \mathrm{~g}^{-1}$ ) of the $\mathrm{Fe}_{2} \mathrm{O}_{3}$ support after the requisite $800{ }^{\circ} \mathrm{C}$ calcination. A higher $1 \mathrm{wt} \%$ loading of the same $2-3 \mathrm{~nm} \mathrm{Pt}$ $\mathrm{NPs}$ (denoted as $1 \mathrm{Pt} / \mathrm{Fe}_{2} \mathrm{O}_{3}-\mathrm{NP}$ ) were also fully transformed into isolated atoms by calcination at $800^{\circ} \mathrm{C}$ (Supplementary Figure $8 \mathrm{a}-\mathrm{b}$ ). Low energy ion scattering (LEIS) evidenced a clear decrease in the $\mathrm{Pt}: \mathrm{Fe}$ atomic ratio in the outermost surface layer upon calcining the stabilizer free $1 \mathrm{Pt} / \mathrm{Fe}_{2} \mathrm{O}_{3}-\mathrm{NP}$ to $800^{\circ} \mathrm{C}$ (Supplementary Figure 9). Since the total Pt loading determined by inductively coupled plasma spectrometry-atomic emission spectrometry (ICP-AES) remained unchanged, it appears that

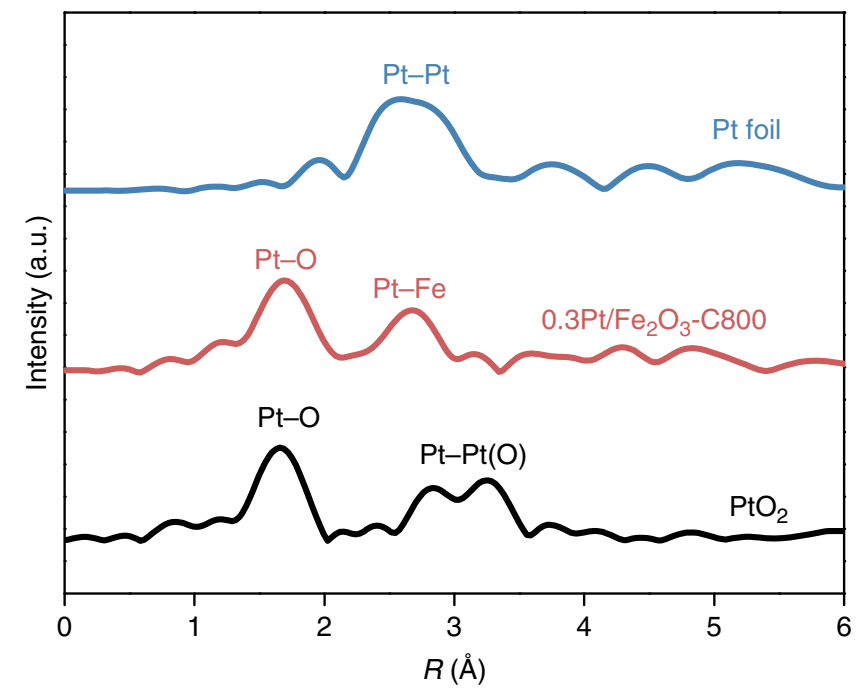

Fig. 2 X-ray absorption spectroscopy of the $0.3 \mathrm{Pt} / \mathrm{Fe}_{2} \mathrm{O}_{3}-\mathrm{C} 800$ catalyst. Fourier transform $\mathrm{Pt} \mathrm{L}_{111}$-edge radial distribution functions of the $0.3 \mathrm{Pt} /$ $\mathrm{Fe}_{2} \mathrm{O}_{3}-\mathrm{C} 800$ catalyst in comparison with $\mathrm{PtO}_{2}$ and $\mathrm{Pt}$ foil some $\mathrm{Pt}$ atoms diffuses into the near sub-surface region of the $\mathrm{Fe}_{2} \mathrm{O}_{3}$ support, possibly by a cation-exchange process ${ }^{52,53}$. However, a further increase in $\mathrm{Pt}$ loading to $2 \mathrm{wt} \%$ resulted in the formation of $\mathrm{Pt}$ clusters alongside isolated atoms (Supplementary Figure $8 \mathrm{c}-\mathrm{d}$ ), in line with the theoretical maximum loading $\left(\sim 1.5 \mathrm{wt} \%\right.$ for $\mathrm{Fe}_{2} \mathrm{O}_{3}$ possessing a surface area of $10 \mathrm{~m}^{2} \mathrm{~g}^{-1}$, see Methods). A high density of clusters and few single isolated atoms were observed for a $4.5 \mathrm{wt} \% \mathrm{Pt}$ loading (Supplementary Figure $8 \mathrm{e}-\mathrm{f}$ ). The maximum concentration of atomically-dispersed Pt loading is clearly dictated by the very low support surface area. The emergence of Pt clusters for loadings $\geq 2$ wt $\%$ confirms that any Pt atoms diffusing into the support must be confined to the immediate subsurface region and not migrated into the bulk $\mathrm{Fe}_{2} \mathrm{O}_{3}$ lattice, since the latter pathway would enable isolated atoms to remain the dominant surface species at far higher Pt loadings.

Disintegration of $\mathrm{Pt}$ NPs during high-temperature calcination was directly visualized by in situ HAADF-STEM, and one $\mathrm{Fe}_{2} \mathrm{O}_{3}$ crystal of $1 \mathrm{Pt} / \mathrm{Fe}_{2} \mathrm{O}_{3}$-NP sample was randomly picked to observe the process. Prior to calcination, about $300 \mathrm{Pt}$ particles were visible across the $\mathrm{Fe}_{2} \mathrm{O}_{3}$ support, and the average particle size was about $3 \mathrm{~nm}$ (Fig. $4 \mathrm{a}-\mathrm{c}$ ). However, after heating to $800^{\circ} \mathrm{C}$ under a flow of 1 bar $\mathrm{O}_{2}$ for $20 \mathrm{~min}$, the total number of Pt NPs decreased to $\sim 200$, since many of the $2-3 \mathrm{~nm}$ Pt NPs shrank and/or disappear entirely, while a few larger particles (size above $10 \mathrm{~nm}$ ) remained (Fig. $4 \mathrm{~b}-\mathrm{c}$ versus Fig. $4 \mathrm{e}-\mathrm{f}$ ). The loss of small clusters was confirmed by higher resolution, time-resolved imaging (Fig. 4g-i taken from the Supplementary Movie 1), which reveal smaller Pt clusters (e.g., particle 1) disintegrated in less than $35 \mathrm{~s}$, while larger Pt clusters (e.g., particle 2) vanished in $45 \mathrm{~s}$. Previous reports suggest that smaller metal crystallites disperse as adatoms, which migrate towards neighboring (larger) particles and eventually coalesce at elevated temperature via Ostwald Ripening, driven by lowering of the total surface energy ${ }^{54}$. In this case, however, particle disappearance occurs in the absence of such coalescence, consistent with the accompanying genesis of atomically-dispersed Pt entities.

DFT Studies. The preceding electron microscopy, X-ray spectroscopy and diffraction, and CO chemisorption measurements provide both clear evidence of, and insight into the driving force for, the formation of atomically-dispersed Pt following high-

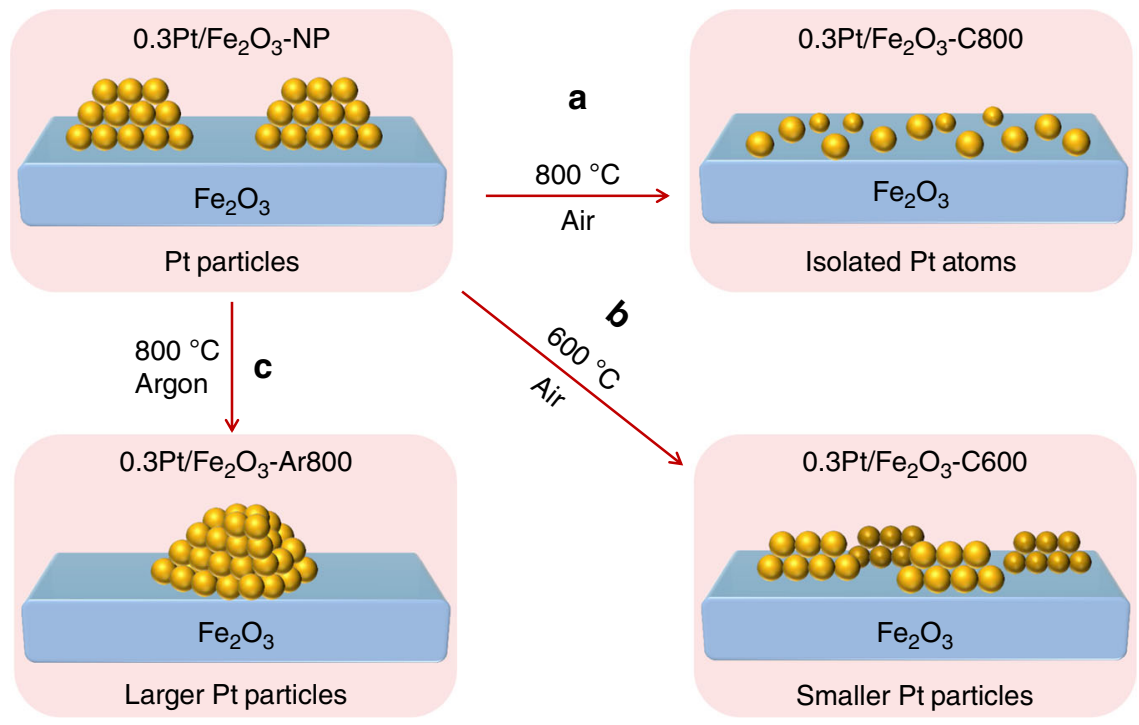

Fig. 3 Illustration of thermally induced Pt nanoparticle restructuring. a, b Calcination under oxygen, or under an inert atmosphere (c), resulting in dispersion as single-atoms or particle sintering, respectively 

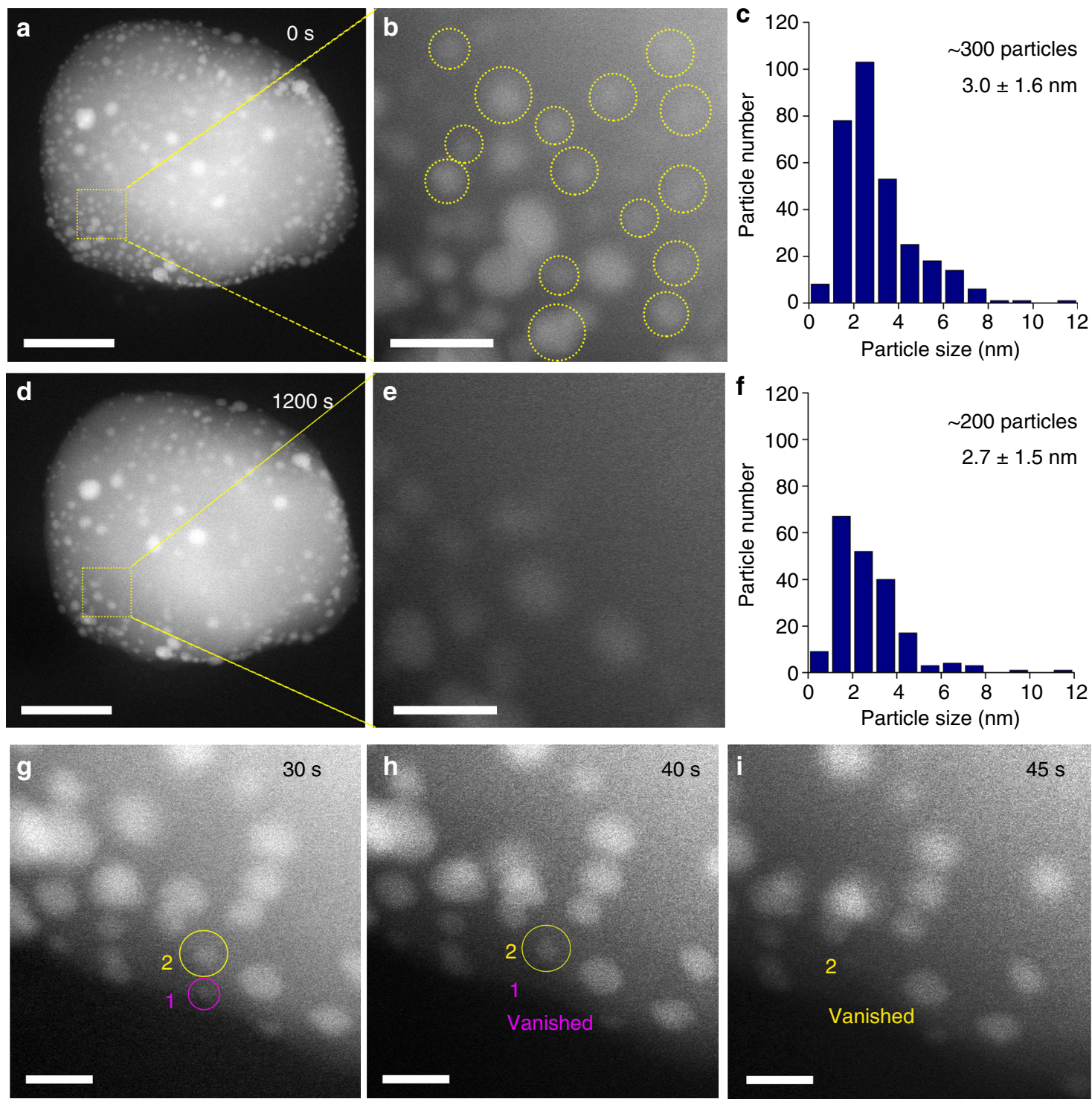

Fig. 4 In situ characterization of Pt NP oxidative dispersion. a-c HAADF-STEM images and size distribution histogram of $1 \mathrm{Pt} / \mathrm{Fe}_{2} \mathrm{O}_{3}-\mathrm{NP}$ before, and $\mathbf{d}-\mathbf{f}$ after in situ calcination at $800^{\circ} \mathrm{C}$ under 1 bar flowing $\mathrm{O}_{2}$ for $20 \mathrm{~min}$ : the yellow squares in panels a and d show the same sample area. A $50 \mathrm{~nm}$ scale bars in a, $\mathbf{d}$ and $10 \mathrm{~nm}$ scale bars in $\mathbf{b}$, e. Yellow circles in panel b highlighted the particles missing after calcination for 20 min. g-i Sequential HAADF-STEM images from the same area showing the dissociation of small particles (labeled by purple and yellow circles) during in situ calcination: $5 \mathrm{~nm}$ scale bars; elapsed time (in seconds) indicated in upper right corner of each image

temperature calcination; NP dispersion is triggered by the formation of $\mathrm{PtO}_{2}$ (Supplementary Figure 6). Computational modeling via DFT calculations (Fig. 5a-b) suggests that the evaporation free energy of $\mathrm{PtO}_{2}$ (the dominant surface species under an oxidizing environment) from a $\mathrm{Pt}(221)$ step (model in Supplementary Figure 10) is about $-0.61 \mathrm{eV}$ per $\mathrm{PtO}_{2}$ at $800^{\circ} \mathrm{C}$, whereas the evaporation energy of $\mathrm{Pt}_{1}$ (the dominant species under inert environments, Supplementary Figure 4d) can reach as high as $4.00 \mathrm{eV}$, and hence is energetically strongly disfavoured due to CMSI of $\mathrm{Pt}_{1}$ to the surface atoms. By comparison, $\mathrm{PtO}_{2}$ evaporation at $600{ }^{\circ} \mathrm{C}$ is virtually thermo-neutral or slightly endothermic $(0.07 \mathrm{eV})$, indicating the critical role of temperature in dispersing Pt NPs. This result is consistent well with the experimental results that the dispersion of NPs only occurred with calcination $>600^{\circ} \mathrm{C}$ (Fig. 3, Supplementary Figures $4 \mathrm{a}-\mathrm{c}$ ).

This temperature-dependent evolution of $\mathrm{PtO}_{2}$ dissociation energetics from a $\mathrm{Pt}(221)$ step (representative of the partially oxidized surface of $\mathrm{Pt}$ NPs following high-temperature calcination) mirrors that of the catalytic activity for methane oxidation, as discussed below. The dissociative adsorption of $\mathrm{PtO}_{2}$ on an oxygen terminated $\mathrm{Fe}_{2} \mathrm{O}_{3}(0001)$ surface (and concomitant desorption of one $\mathrm{O}_{2}$ molecule) is highly exothermic at $800{ }^{\circ} \mathrm{C}$ (calculated as $-2.46 \mathrm{eV}$, Fig. $5 \mathrm{c}-\mathrm{d}$ ), with $\mathrm{PtO}_{2}$ dissociative capture even more favorable at lower temperature. Note that the evaporation, migration, and trapping do not require the presence of anion or cation vacancies on the support: no Lewis acid sites were detected on the $\mathrm{Fe}_{2} \mathrm{O}_{3}$ support by $\mathrm{NH}_{3}$ temperatureprogrammed desorption, suggesting that $\mathrm{Fe}_{2} \mathrm{O}_{3}$ possessed negligible oxygen anion defects following a high-temperature calcination. Therefore, $\mathrm{Pt}$ atoms disperse across the ferric oxide support where they are anchored as isolated atoms through a strong local surface interaction. Calculations indicate that these reactivelyformed Pt atoms coordinate with four surface oxygen atoms in a distorted square geometry with an average Pt-O length of $1.94 \AA$, intermediate between that in gas $\mathrm{PtO}_{2}(\mathrm{CN}=2,1.70 \AA)$ and bulk $\mathrm{PtO}_{2}(\mathrm{CN}=6,2.04 \AA)$. Bader charge analysis of an isolated $\mathrm{Pt}$ 

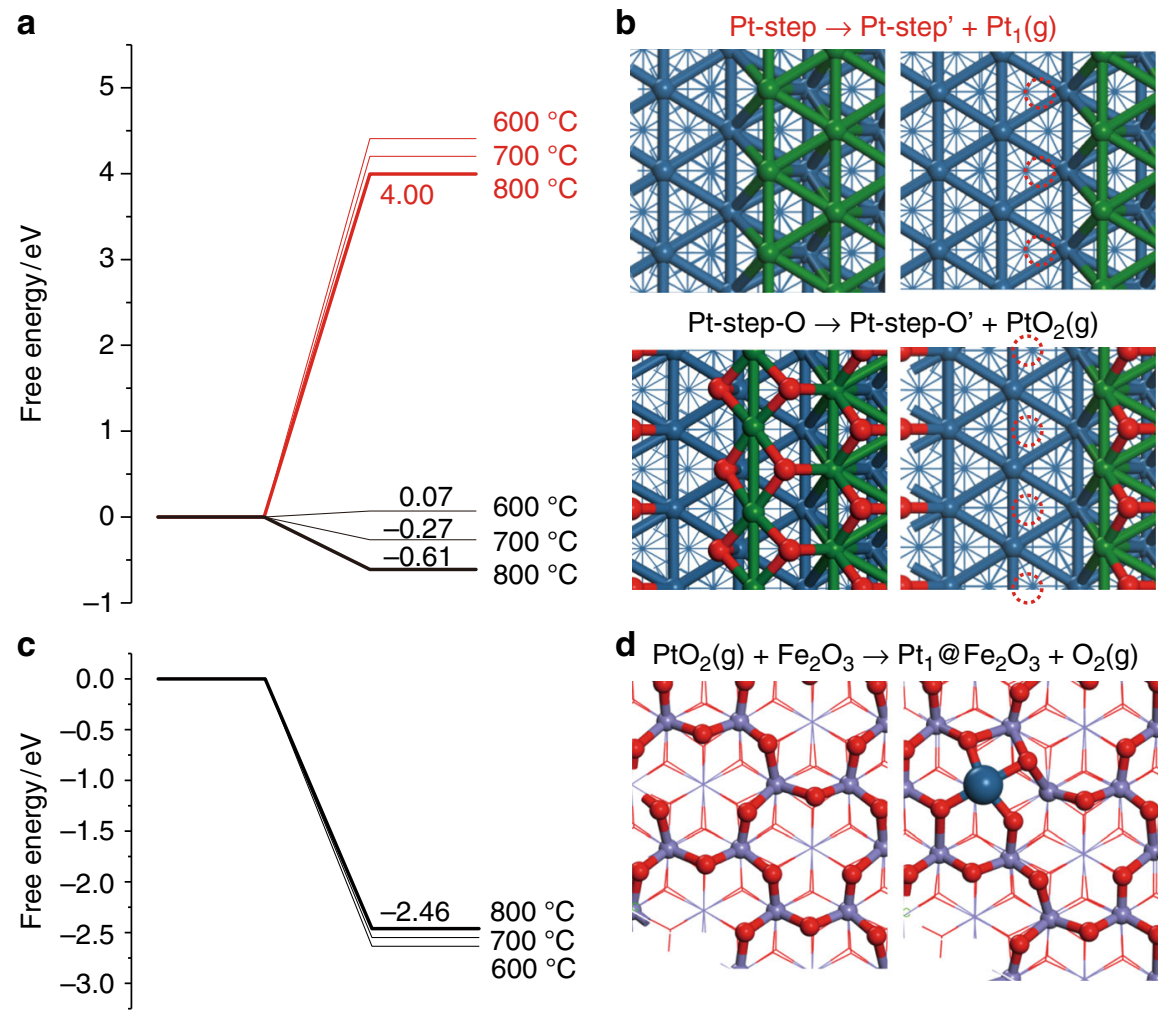

Fig. 5 Optimized structures and energy profiles for Pt NP dispersion as isolated Pt atoms. a, b Calculated energies and surface structures for evaporation of a single $\mathrm{Pt}$ atom $\left(\mathrm{Pt}_{1}\right)$ from a $\mathrm{Pt}(221)$ step (red value) or evaporation of a $\mathrm{PtO}_{2}$ species from an oxygen pre-covered $\mathrm{Pt}(221)$ step (black values).

c, $\mathbf{d}$ Calculated energies and surface structures for dissociative capture of $\mathrm{PtO}_{2}$ over $\mathrm{Fe}_{2} \mathrm{O}_{3}(0001)$ surface and concomitant formation of a $\mathrm{Pt}$ atom and evolved $\mathrm{O}_{2}$. Color code: outermost layer Pt (green); second layer Pt (blue); O (red); Fe (purple)

atom on $\mathrm{Fe}_{2} \mathrm{O}_{3}(0001)$ shows a charge of $+1.43|\mathrm{e}|$, approximating to but slightly lower than the charge of $\mathrm{Pt}$ in gas $\mathrm{PtO}_{2}$ and bulk $\mathrm{PtO}_{2}$ (Supplementary Table 2), consistent with tetravalent $\mathrm{Pt}$ and the XPS analysis (Supplementary Figure 6). The total free energy change for the formation of $\mathrm{Fe}_{2} \mathrm{O}_{3}$ stabilized isolated $\mathrm{Pt}$ atoms from Pt NPs is $-3.07 \mathrm{eV}$ per $\mathrm{Pt}$ atom at $800{ }^{\circ} \mathrm{C}$, i.e. such a dispersion is strongly exothermic with low barrier. In comparison, Pt only interacts very weakly (low endothermic free energy) with an alumina surface (Supplementary Figures 11-13, Supplementary Table 3 ). By comparing the charge density difference of $\mathrm{Pt}_{1} / \mathrm{Fe}_{2} \mathrm{O}_{3}(0001)$ and $\mathrm{Pt}_{1} / \mathrm{Al}_{2} \mathrm{O}_{3}(010)$, defined as $\Delta \rho=\rho_{\mathrm{Pt}+\text { slab }}-$ $\rho_{\text {slab }}-\rho_{\mathrm{Pt}}$, four strong chemical bonds are observed between $\mathrm{Pt}$ and adjacent $\mathrm{O}$ atoms by covalent $(d-p)$ orbital interactions at the $\mathrm{Fe}_{2} \mathrm{O}_{3}$ surface. In contrast, only very weak $\mathrm{Pt}-\mathrm{O}$ interactions occur at the $\mathrm{Al}_{2} \mathrm{O}_{3}$ surface, resulting in $\mathrm{Pt}-\mathrm{O}$ bond lengths much longer than that on $\mathrm{Fe}_{2} \mathrm{O}_{3}$. Bader analysis indicates that each $\mathrm{Pt}$ possesses a $-0.14|\mathrm{e}|$ charge, i.e. approximately metallic character (Supplementary Table 2); both findings are attributed to the irreducibility of $\mathrm{Al}^{3+}$, i.e. strong non-redox $\mathrm{Al}-\mathrm{O}$ bonding network, which prevents any significant metal-support interaction. DFT calculations are hence in excellent agreement with experimental observations. The finding of the stability of SAC closely related to the reducibility of the support is consistent with previous work as well ${ }^{55}$.

Catalytic performance in methane combustion. The impact of oxygen-induced restructuring at elevated temperature on catalytic performance is striking (Fig. 6). As the reaction temperature of $1 \mathrm{Pt} / \mathrm{Fe}_{2} \mathrm{O}_{3}-\mathrm{NP}$ under an oxygen-rich methane gas feed was raised from 300 to $700{ }^{\circ} \mathrm{C}$, the combustion activity increased such that a modest $\sim 18 \%$ conversion was initially attained. However, in contrast to most catalytic reactions wherein activity subsequently

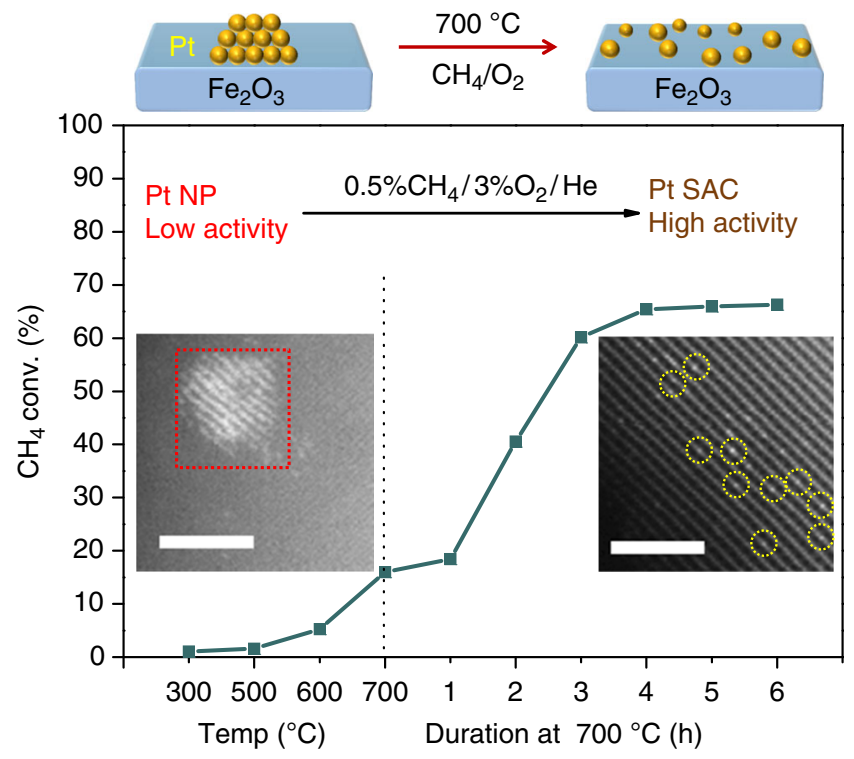

Fig. 6 Dynamic formation of a Pt SAC during methane oxidation. Light-off curve of $1 \mathrm{Pt} / \mathrm{Fe}_{2} \mathrm{O}_{3}-\mathrm{NP}$ for methane oxidation with a feed gas comprising 0.5 vol\% $\mathrm{CH}_{4} / 3$ vol\% $\mathrm{O}_{2} / 97$ vol\% He balance at $30 \mathrm{mLmin}^{-1}$. STEM images of catalyst before (left-inset) and after (right-inset) reaction. Scale bars, $2 \mathrm{~nm}$. Red square and yellow circles are used to indicate the Pt NP and Pt atoms, respectively

decreases with time-on-stream, the activity of $1 \mathrm{Pt} / \mathrm{Fe}_{2} \mathrm{O}_{3}-\mathrm{NP}$ displayed a monotonic increase over the following $4 \mathrm{~h}$ at $700{ }^{\circ} \mathrm{C}$ to reach $65 \%$ conversion. Post-reaction catalyst characterization confirmed that this high-temperature catalyst activation was 
accompanied by the disappearance of Pt NPs present in the asprepared material (Fig. 6 left inset), and formation of atomicallydispersed Pt (Fig. 6 right inset, Supplementary Figure 14a-b), demonstrating a causal relationship between in situ genesis of a $\mathrm{Pt}$ SAC and dramatically enhanced performance. Note that preactivation of $1 \mathrm{Pt} / \mathrm{Fe}_{2} \mathrm{O}_{3}-\mathrm{NP}$ by calcination at $700{ }^{\circ} \mathrm{C}$ for $5 \mathrm{~h}$ prior to methane addition resulted in an extremely stable Pt SAC that maintained similar activity for $>16 \mathrm{~h}$ on-stream (Supplementary Figure $14 \mathrm{c}$ ). Since the mass of $1 \mathrm{Pt} / \mathrm{Fe}_{2} \mathrm{O}_{3}-\mathrm{NP}$ catalyst (and $\mathrm{Pt}$ loading) in this methane light-off experiment is constant, the time-dependent increase in $\mathrm{CH}_{4}$ conversion at $700{ }^{\circ} \mathrm{C}$ due to catalyst restructuring is directly proportional to the catalytic activity; single-atom formation induces a four-fold enhancement $(18 \rightarrow 65 \%$ conversion) in the specific activity. Additional experiments with the same catalyst at $20 \%$ iso-conversion in either its SAC (1Pt/ $\left./ \mathrm{Fe}_{2} \mathrm{O}_{3}-\mathrm{C} 700\right)$ or nanoparticulate $\left(1 \mathrm{Pt} / \mathrm{Fe}_{2} \mathrm{O}_{3}-\mathrm{NP}\right)$ form confirmed that the specific activity of the former was 4 times greater than that of the latter $\left(2.01 \mathrm{~mol}_{\mathrm{CH} 4} \mathrm{~h}^{-1} \mathrm{~g}_{\mathrm{Pt}}{ }^{-1} \mathrm{vs}\right.$. $0.47 \mathrm{~mol}_{\mathrm{CH} 4} \mathrm{~h}^{-1} \mathrm{~g}_{\mathrm{Pt}}{ }^{-1}$ ) and 20 times than that reported for Pt/ $\mathrm{Al}_{2} \mathrm{O}_{3}{ }^{56}$ (Supplementary Table 4). Turnover frequencies based on the number of surface $\mathrm{Pt}$ atoms (dispersion) were similar for SAC and nanoparticulate counterparts $\left(0.1 \mathrm{~s}^{-1}\right.$ vs. $\left.0.08 \mathrm{~s}^{-1}\right)$, indicating a common active site, and hence the superior specific activity of the single-atom catalyst reflects its improved atom efficiency (every $\mathrm{Pt}$ atom directly activates methane).

Interaction between $\mathrm{Pt}$ atoms and iron-modified support. Fundamental insight into the reaction-induced restructuring of metal NPs over a reducible metal oxide support offers a facile route to synthesize high-loading and thermally stable SACs. Platinum NPs introduced either as pre-formed colloids or e.g. by simple wet impregnation with $1 \mathrm{wt} \% \mathrm{H}_{2} \mathrm{PtCl}_{6}$ (Supplementary Figure 15a-b) over a low area $\mathrm{Fe}_{2} \mathrm{O}_{3}$ support, are readily transformed into isolated $\mathrm{Pt}$ atoms by high-temperature calcination (Supplementary Figure 15c-d). Flytzani-Stephanopoulos and coworkers have shown that $\mathrm{Na}$ or $\mathrm{K}$ ions can stabilize surface hydroxyls, which can in turn stabilize metal $(\mathrm{Au}$ and $\mathrm{Pt})$ atoms and/or subnanometer clusters over diverse supports ${ }^{57-59}$. However, our recent work ${ }^{60}$ has not identified such a role for alkalis, suggesting that $\mathrm{Fe}_{2} \mathrm{O}_{3}$ may have unique properties to some degree. To test our hypothesis, we synthesized a sodium-free material using a $\left(\mathrm{NH}_{4}\right)_{2} \mathrm{CO}_{3}$ precipitant, denoted as $\mathrm{Fe}_{2} \mathrm{O}_{3}(\mathrm{~N})$. Pt $\mathrm{NPs}$ exhibited the same dispersion and single-atom formation after $800^{\circ} \mathrm{C}$ calcination over this $\mathrm{Fe}_{2} \mathrm{O}_{3}(\mathrm{~N})$ support (Supplementary Figure 16), confirming that the reducible $\mathrm{Fe}_{2} \mathrm{O}_{3}$ support, and not presence of $\mathrm{Na}^{+}$, was responsible for stabilizing Pt singleatoms.

The propensity for stabilizing single $\mathrm{Pt}$ atoms is dictated by the magnitude of the metal-support interaction, which itself can be tuned by e.g. doping a reducible $\left(\mathrm{Fe}_{2} \mathrm{O}_{3}\right)$ into a non-reducible $\left(\mathrm{Al}_{2} \mathrm{O}_{3}\right)$ oxide (Supplementary Figure 17a) through coprecipitation. As shown in Fig. 7, functionalization of such an $\mathrm{Fe}_{2} \mathrm{O}_{3}-\mathrm{Al}_{2} \mathrm{O}_{3}$ mixed metal oxide by Pt NPs, and subsequent $800^{\circ} \mathrm{C}$ calcination, delivers atomically-dispersed $\mathrm{Pt}$ precisely as observed over the pure ferric oxide (Supplementary Figure 17b-c), but in a higher area form $\left(\sim 30 \mathrm{~m}^{2} \mathrm{~g}^{-1}\right)$.

\section{Discussion}

We reported a facile synthesis of thermally-stable Pt SAC that achieved remarkable catalytic performance towards methane combustion. Isolated $\mathrm{Pt}$ atoms with high oxidation state are not stabilized by surface defects but through a strong covalent interaction with iron and oxygen atoms on the surface. Since Fe can be simply incorporated into a variety of oxides with low area and/or defect density, e.g. perovskites and spinels, our approach

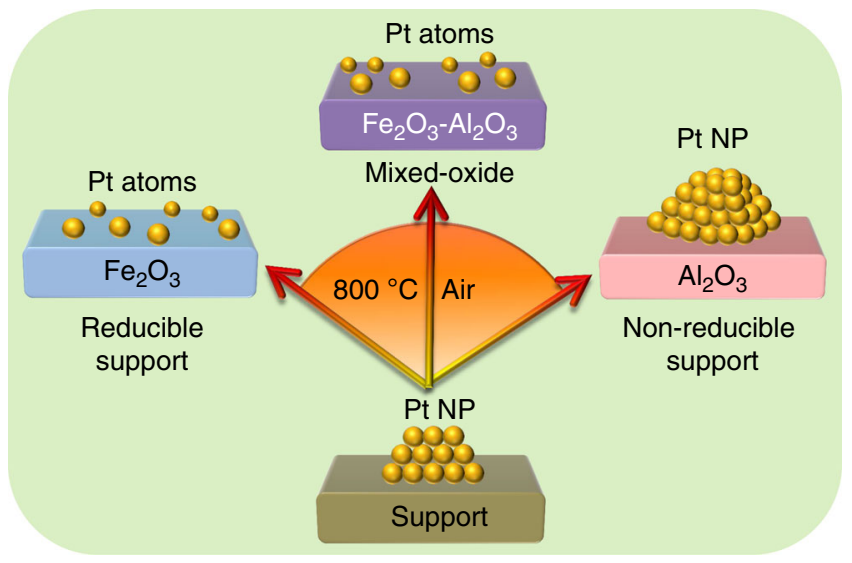

Fig. 7 Illustration of Pt NP sintering/dispersing on different supports. Metal oxide reducibility dictates the ability of a support to anchor isolated $\mathrm{Pt}$ atoms: $\mathrm{Fe}_{2} \mathrm{O}_{3}$ favors atomically dispersed $\mathrm{Pt}$, whereas $\mathrm{Al}_{2} \mathrm{O}_{3}$ favors nanoparticle sintering. Doping iron oxide into non-reducible support $\left(\mathrm{Fe}_{2} \mathrm{O}_{3}-\mathrm{Al}_{2} \mathrm{O}_{3}\right)$ can adjust noble metal dispersion

may afford a generic route to fabricate high loading Pt SACs over diverse supports being able to operate under harsh reaction conditions.

\section{Methods}

Synthesis of $\mathbf{F e O}$ and $\mathbf{F e}_{\mathbf{2}} \mathbf{O}_{\mathbf{3}}$. Ferric nitrate $\left(\mathrm{Fe}\left(\mathrm{NO}_{3}\right)_{3} \cdot 9 \mathrm{H}_{2} \mathrm{O}\right), 98 \%$, SigmaAldrich) and sodium carbonate $\left(\mathrm{Na}_{2} \mathrm{CO}_{3}, 99.5 \%\right.$ Sigma-Aldrich) were used as purchased. An aqueous solution of $\mathrm{Fe}\left(\mathrm{NO}_{3}\right)_{3}(1 \mathrm{~mol} \mathrm{~L}-1)$ was obtained by dissolving $\mathrm{Fe}\left(\mathrm{NO}_{3}\right)_{3} \cdot 9 \mathrm{H}_{2} \mathrm{O}(122 \mathrm{~g}, 0.3 \mathrm{~mol})$ in deionized water $(300 \mathrm{~mL}) . \mathrm{FeO}_{x}$ was subsequently prepared from this solution by precipitation. First, $\mathrm{Na}_{2} \mathrm{CO}_{3}(11 \mathrm{~g})$ was added in water $(100 \mathrm{~mL})$ and stabilized at $50^{\circ} \mathrm{C}$ in a water bath. To this, $40 \mathrm{~mL} \mathrm{Fe}$ $\left(\mathrm{NO}_{3}\right)_{3}$ solution was slowly added $\left(1 \mathrm{~mL} \mathrm{~min}{ }^{-1}\right)$ under vigorous stirring at $50^{\circ} \mathrm{C}$ for $3 \mathrm{~h}$, and then aged static for a further $2 \mathrm{~h}$. The recovered $\mathrm{FeO}_{x}$ solid was washed with deionized water and dried at $60^{\circ} \mathrm{C}$ overnight. $\mathrm{Fe}_{2} \mathrm{O}_{3}$ was obtained by calcining $\mathrm{FeO}_{x}$ at $800^{\circ} \mathrm{C}\left(\operatorname{ramp}\right.$ rate $\left.3{ }^{\circ} \mathrm{C} \mathrm{min}^{-1}\right)$ for $5 \mathrm{~h}$ under flowing air $\left(100 \mathrm{~mL} \mathrm{~min}^{-1}\right)$.

Synthesis of $\mathrm{Fe}_{\mathbf{2}} \mathbf{O}_{\mathbf{3}} \mathbf{( N )}$. Ferric nitrate $\left(\mathrm{Fe}\left(\mathrm{NO}_{3}\right)_{3} \cdot 9 \mathrm{H}_{2} \mathrm{O}\right), 98 \%$, Sigma-Aldrich) and ammonium carbonate (Sigma-Aldrich, $\left(\mathrm{NH}_{4}\right)_{2} \mathrm{CO}_{3} 99.5 \%$ ) were used as purchased. First, $\left(\mathrm{NH}_{4}\right)_{2} \mathrm{CO}_{3}(4 \mathrm{~g})$ was added in water $(6 \mathrm{~mL})$ and stabilized at $50^{\circ} \mathrm{C}$ in a water bath. To this, $20 \mathrm{~mL} \mathrm{Fe}\left(\mathrm{NO}_{3}\right)_{3}$ solution $\left(1 \mathrm{~mol} \mathrm{~L}^{-1}\right)$ was slowly added $\left(1 \mathrm{~mL} \mathrm{~min}^{-1}\right)$ under vigorous stirring at $50^{\circ} \mathrm{C}$ for $3 \mathrm{~h}$, and then aged static for a further $2 \mathrm{~h}$. The recovered $\mathrm{FeO}_{x}$ solid was washed with deionized water and dried at $60^{\circ} \mathrm{C}$ overnight. $\mathrm{Fe}_{2} \mathrm{O}_{3}(\mathrm{~N})$ was obtained by calcining $\mathrm{FeO}_{x}$ at $800^{\circ} \mathrm{C}\left(\right.$ ramp rate $\left.3^{\circ} \mathrm{C} \mathrm{min}^{-1}\right)$ for $5 \mathrm{~h}$ under flowing air $\left(100 \mathrm{~mL} \mathrm{~min}^{-1}\right)$ to obtain the $\mathrm{Na}^{+}$-free support.

Synthesis of $\mathbf{F e}_{\mathbf{2}} \mathbf{O}_{\mathbf{3}}-\mathbf{A l}_{\mathbf{2}} \mathbf{O}_{\mathbf{3}}$. An $\mathrm{Fe}_{2} \mathrm{O}_{3}-\mathrm{Al}_{2} \mathrm{O}_{3}$ mixed oxide was synthesized by coprecipitation. $\mathrm{Fe}\left(\mathrm{NO}_{3}\right)_{3} \cdot 9 \mathrm{H}_{2} \mathrm{O}(8 \mathrm{~g}, 0.02 \mathrm{~mol})$ and $\mathrm{Al}\left(\mathrm{NO}_{3}\right)_{3} \cdot 9 \mathrm{H}_{2} \mathrm{O}(7.5 \mathrm{~g}, 0.02 \mathrm{~mol}$ $98 \%$, Sigma-Aldrich) were first dissolved in $80 \mathrm{~mL}$ deionized water. Separately, $\left(\mathrm{NH}_{4}\right)_{2} \mathrm{CO}_{3}$ (7.7 g, $0.08 \mathrm{~mol}, 99 \%$, Sigma-Aldrich) was dissolved in $80 \mathrm{~mL}$ deionized water. The two aqueous solutions were combined in $30 \mathrm{~mL}$ water at $50^{\circ} \mathrm{C}$ under stirring for $3 \mathrm{~h}$, and then aged static for a further $2 \mathrm{~h}$. The resulting solid was recovered by filtration, washed with deionized water, dried at $60^{\circ} \mathrm{C}$ overnight, and finally calcined at $800^{\circ} \mathrm{C}\left(\right.$ ramp rate $3{ }^{\circ} \mathrm{C} \mathrm{min}-1$ ) for $5 \mathrm{~h}$ under flowing air $\left(100 \mathrm{~mL} \mathrm{~min}^{-1}\right)$.

Synthesis of $\mathbf{P t}_{\mathbf{1}} / \mathbf{F e O}_{\boldsymbol{x}}$ and $\mathbf{\mathbf { P t } _ { \mathbf { 1 } }} / \mathbf{F e O} \mathbf{O}_{\boldsymbol{x}} \mathbf{- C 8 0 0}$. $\mathrm{Pt}_{\mathbf{1}} / \mathrm{FeO}_{x}$ was prepared by coprecipitation of an aqueous mixture of chloroplatinic acid $\left(\mathrm{H}_{2} \mathrm{PtCl}_{6} \cdot 6 \mathrm{H}_{2} \mathrm{O}, 37 \mathrm{mg}_{\mathrm{Pt}}\right.$ $\mathrm{mL}^{-1}, 2.6 \mathrm{~mL}, 99.9 \%$, Sigma-Aldrich) and $\mathrm{Fe}\left(\mathrm{NO}_{3}\right)_{3} \cdot 9 \mathrm{H}_{2} \mathrm{O}\left(1 \mathrm{~mol} \mathrm{~L}{ }^{-1}, 40 \mathrm{~mL}\right)$ with $\mathrm{Na}_{2} \mathrm{CO}_{3}$ solution $\left(11 \mathrm{~g} \mathrm{Na}_{2} \mathrm{CO}_{3}\right.$ in $100 \mathrm{~mL} \mathrm{H}_{2} \mathrm{O}$ ) at $50^{\circ} \mathrm{C}$ under stirring for $3 \mathrm{~h}$, and ageing static for a further $2 \mathrm{~h}$. The resulting solid was recovered by filtration, washed with deionized water and dried at $60^{\circ} \mathrm{C}$ overnight. A portion of the $\mathrm{Pt}_{1} / \mathrm{FeO}_{x}$ was then calcined as above at $800{ }^{\circ} \mathrm{C}$ and denoted as $\mathrm{Pt}_{1} / \mathrm{FeO}_{x}-\mathrm{C} 800$. The Pt loading determined by ICP was $1.8 \mathrm{wt} \%$.

Synthesis of $x \mathrm{Pt} / \mathrm{Fe}_{2} \mathrm{O}_{3}-\mathrm{NP}$ and $\boldsymbol{x P t} / \mathrm{Fe}_{2} \mathrm{O}_{3}-\mathbf{C 8 0 0}$. Pt nanoparticles (NPs) were synthesized according to the literature ${ }^{61}$. Typically, an ethylene glycol solution of $\mathrm{NaOH}\left(0.5 \mathrm{~mol} \mathrm{~L}^{-1}\right)$ was added into an ethylene glycol solution of $\mathrm{H}_{2} \mathrm{PtCl}_{6} \cdot 6 \mathrm{H}_{2} \mathrm{O}$ under stirring $\left(3.7 \mathrm{mg}_{\mathrm{pt}} \mathrm{mL}^{-1}\right)$. The resulting transparent yellow platinum colloidal solution was heated at $160^{\circ} \mathrm{C}$ for $3 \mathrm{~h}$ under flowing Ar to form a transparent dark-brown platinum colloidal solution. Separately, $\mathrm{Fe}_{2} \mathrm{O}_{3}$ was dispersed in deionized water by sonication, to which the Pt NP colloidal solution was added, and the 
resulting solid dried overnight at $100^{\circ} \mathrm{C}$, and then calcined at $500{ }^{\circ} \mathrm{C}$ for $5 \mathrm{~h}$ under flowing air to remove the glycol stabilizer. A series of Pt NP catalysts were prepared with different Pt loadings, denoted as $x \mathrm{Pt}^{-} \mathrm{Fe}_{2} \mathrm{O}_{3}-\mathrm{NP}(x=0.3,1,2$, or $4.5 \mathrm{wt} \% \mathrm{Pt}$ as determined by ICP). $x \mathrm{Pt} / \mathrm{Fe}_{2} \mathrm{O}_{3}-\mathrm{C} 800$ was obtained by treating $x \mathrm{Pt} / \mathrm{Fe}_{2} \mathrm{O}_{3}-\mathrm{NP}$ under flowing air $\left(100 \mathrm{~mL} \mathrm{~min}^{-1}\right)$ at $800^{\circ} \mathrm{C}$ for $5 \mathrm{~h}$.

Synthesis of $\mathbf{P t} / \mathbf{A l}_{\mathbf{2}} \mathbf{O}_{\mathbf{3}}-\mathbf{N P}$ and $\mathbf{P t} / \mathbf{A l}_{\mathbf{2}} \mathbf{O}_{\mathbf{3}}-\mathbf{C 8 0 0}$. $\mathrm{Pt} / \mathrm{Al}_{2} \mathrm{O}_{3}-\mathrm{NP}$ was prepared following the above procedure by dispersing colloidal $\mathrm{Pt}$ over the $\mathrm{Al}_{2} \mathrm{O}_{3}$ support at a Pt loading of $0.3 \mathrm{wt} \%$ as determined by ICP, and then calcined at $300^{\circ} \mathrm{C}$ for $5 \mathrm{~h}$ under flowing air. $\mathrm{Pt} / \mathrm{Al}_{2} \mathrm{O}_{3}-\mathrm{C} 800$ was obtained by treating $\mathrm{Pt} / \mathrm{Al}_{2} \mathrm{O}_{3}-\mathrm{NP}$ under flowing air $\left(100 \mathrm{~mL} \mathrm{~min}^{-1}\right)$ at $800^{\circ} \mathrm{C}$ for $5 \mathrm{~h}$.

Synthesis of $\mathbf{P t} / \mathrm{Fe}_{\mathbf{2}} \mathrm{O}_{\mathbf{3}}-\mathrm{Al}_{\mathbf{2}} \mathrm{O}_{\mathbf{3}}-\mathrm{NP}$ and $\mathrm{Pt} / \mathrm{Fe}_{\mathbf{2}} \mathrm{O}_{\mathbf{3}}-\mathrm{Al}_{\mathbf{2}} \mathrm{O}_{\mathbf{3}}-\mathbf{C 8 0 0}$. $\mathrm{Pt} / \mathrm{Fe}_{2} \mathrm{O}_{3}-\mathrm{Al}_{2} \mathrm{O}_{3}$ $\mathrm{NP}$ and $\mathrm{Pt} / \mathrm{Fe}_{2} \mathrm{O}_{3}-\mathrm{Al}_{2} \mathrm{O}_{3}-\mathrm{C} 800$ were prepared following the above procedure by dispersing colloidal Pt over the $\mathrm{Fe}_{2} \mathrm{O}_{3}-\mathrm{Al}_{2} \mathrm{O}_{3}$ support at a Pt loading of $0.5 \mathrm{wt} \%$ as determined by ICP.

Synthesis of $\mathbf{0 . 3 P t} / \mathrm{Fe}_{\mathbf{2}} \mathbf{O}_{\mathbf{3}}-\mathbf{C 6 0 0}$ and $\mathbf{0 . 3 P t} / \mathrm{Fe}_{\mathbf{2}} \mathbf{O}_{\mathbf{3}}-\mathbf{A r 8 0 0}$. $0.3 \mathrm{Pt} / \mathrm{Fe}_{2} \mathrm{O}_{3}-\mathrm{C} 600$ was obtained by treating $0.3 \mathrm{Pt} / \mathrm{Fe}_{2} \mathrm{O}_{3}-\mathrm{NP}$ under flowing air $\left(100 \mathrm{~mL} \mathrm{~min}^{-1}\right)$ at $600{ }^{\circ} \mathrm{C}$ for 5 h. $0.3 \mathrm{Pt} / \mathrm{Fe}_{2} \mathrm{O}_{3}-\mathrm{Ar} 800$ was obtained by treating $0.3 \mathrm{Pt} / \mathrm{Fe}_{2} \mathrm{O}_{3}-\mathrm{NP}$ under flowing $\operatorname{Ar}\left(100 \mathrm{~mL} \mathrm{~min}^{-1}\right)$ at $800^{\circ} \mathrm{C}$ for $5 \mathrm{~h}$.

Synthesis of $\mathrm{H}_{2} \mathrm{PtCl}_{6} / \mathrm{Fe}_{2} \mathrm{O}_{3}$ and $\mathrm{H}_{2} \mathrm{PtCl}_{6} / \mathrm{Fe}_{2} \mathrm{O}_{3}-\mathrm{C800}$. In a typical procedure, $1 \mathrm{~g} \mathrm{Fe}_{2} \mathrm{O}_{3}$ was dispersed in $5 \mathrm{~mL}$ deionized water by sonication, to which $0.3 \mathrm{~mL}$ $\mathrm{H}_{2} \mathrm{PtCl}_{6}$ aqueous solution $\left(37 \mathrm{mg}_{\mathrm{Pt}} \mathrm{mL}^{-1}\right)$ was added. Water was gradually evaporated by heating the resulting suspension at $80^{\circ} \mathrm{C}$. The resulting solid was calcined at $300{ }^{\circ} \mathrm{C}$ for $5 \mathrm{~h}$ under flowing air $\left(100 \mathrm{~mL} \mathrm{~min}^{-1}\right)$ and denoted as $\mathrm{H}_{2} \mathrm{PtCl}_{6} /$ $\mathrm{Fe}_{2} \mathrm{O}_{3}$. The Pt loading was $1 \mathrm{wt} \%$ as determined by ICP. A portion of $\mathrm{H}_{2} \mathrm{PtCl}_{6} /$ $\mathrm{Fe}_{2} \mathrm{O}_{3}$ was also heated at $800{ }^{\circ} \mathrm{C}$ under flowing air $\left(100 \mathrm{~mL} \mathrm{~min}^{-1}\right)$ for $5 \mathrm{~h}$ to generate $\mathrm{H}_{2} \mathrm{PtCl}_{6} / \mathrm{Fe}_{2} \mathrm{O}_{3}-\mathrm{C} 800$

Synthesis of $\mathrm{H}_{2} \mathrm{PtCl}_{6} / \mathrm{Fe}_{2} \mathrm{O}_{3}(\mathrm{~N})$ and $\mathrm{H}_{2} \mathrm{PtCl}_{6} / \mathrm{Fe}_{2} \mathrm{O}_{3}(\mathrm{~N})$-C800. In a typical procedure, $150 \mathrm{mg} \mathrm{Fe} \mathrm{O}_{3}(\mathrm{~N})$ was dispersed in $2 \mathrm{~mL}$ deionized water by sonication, to which $0.013 \mathrm{~mL} \mathrm{H}_{2} \mathrm{PtCl}_{6}$ aqueous solution $\left(37 \mathrm{mg}_{\mathrm{Pt}} \mathrm{mL}^{-1}\right)$ was added. Water was gradually evaporated by heating the resulting suspension at $80^{\circ} \mathrm{C}$. The resulting solid was calcined at $300^{\circ} \mathrm{C}$ for $5 \mathrm{~h}$ under flowing air $\left(100 \mathrm{~mL} \mathrm{~min}^{-1}\right)$ and denoted as $\mathrm{H}_{2} \mathrm{PtCl}_{6} / \mathrm{Fe}_{2} \mathrm{O}_{3}(\mathrm{~N})$. The Pt loading was $0.2 \mathrm{wt} \%$ as determined by ICP. A portion of $\mathrm{H}_{2} \mathrm{PtCl}_{6} / \mathrm{Fe}_{2} \mathrm{O}_{3}$ was also heated at $800{ }^{\circ} \mathrm{C}$ under flowing air $\left(100 \mathrm{~mL} \mathrm{~min}^{-1}\right)$ for $5 \mathrm{~h}$ to generate $\mathrm{H}_{2} \mathrm{PtCl}_{6} / \mathrm{Fe}_{2} \mathrm{O}_{3}(\mathrm{~N})-\mathrm{C} 800$.

Synthesis of $\mathbf{H}_{\mathbf{2}} \mathbf{P t C l} 6 / \mathbf{A l}_{\mathbf{2}} \mathbf{O}_{\mathbf{3}}$ and $\mathbf{H}_{\mathbf{2}} \mathbf{P t C l} \mathbf{C l}_{6} / \mathbf{A l}_{\mathbf{2}} \mathbf{O}_{\mathbf{3}}-\mathbf{C 8 0 0}$. $\alpha-\mathrm{Al}_{2} \mathrm{O}_{3}$ (99.5\%, SigmaAldrich) was used as purchased. $\mathrm{H}_{2} \mathrm{PtCl}_{6} / \mathrm{Al}_{2} \mathrm{O}_{3}$ and $\mathrm{H}_{2} \mathrm{PtCl}_{6} / \mathrm{Al}_{2} \mathrm{O}_{3}$ - $\mathrm{C} 800$ were prepared following the above procedure by dispersing $\mathrm{H}_{2} \mathrm{PtCl}_{6}$ over the $\alpha-\mathrm{Al}_{2} \mathrm{O}_{3}$ support. The Pt loading was $1 \mathrm{wt} \%$ as determined by ICP.

Characterization. Pt loadings were determined by inductively coupled plasma spectrometry-atomic emission spectrometry (ICP-AES) on an IRIS Intrepid II XSP instrument (Thermo Electron Corporation). X-ray diffraction (XRD) patterns were collected on a PW3040/60 X'Pert Pro super (PANalytical) diffractometer, operating at $40 \mathrm{kV}$ and $40 \mathrm{~mA}$ using a $\mathrm{Cu} \mathrm{Ka}$ radiation source $(\lambda=0.15432 \mathrm{~nm})$ with a scanning angle $(2 \theta)$ of $10-80^{\circ}$. In situ diffuse reflectance infrared Fourier transform spectra (DRIFTS) were collected at $25^{\circ} \mathrm{C}$ with a Bruker Vertex 70 spectrometer equipped with a mercury cadmium telluride (MCT) detector at a resolution of $4 \mathrm{~cm}^{-1}$ over 32 scans. Samples were first heated in situ at $200^{\circ} \mathrm{C}$ under flowing $\mathrm{He}$ for $0.5 \mathrm{~h}$, then cooled to room temperature prior to recording of background spectra. Subsequently, a $1 \mathrm{vol} \% \mathrm{CO} / \mathrm{He}$ flow was introduced to the sample for $10 \mathrm{~min}$. The environmental cell was then purged with flowing helium to remove gas phase CO, prior to spectral acquisition of chemisorbed $\mathrm{CO}$ species. Temperatureprogrammed desorption (TPD) was conducted on a Micromeritics AutoChem II 2910 automatic catalyst characterization system equipped with a mass spectrometer. First, the $\mathrm{Fe}_{2} \mathrm{O}_{3}$ support was loaded into a $\mathrm{U}$-shape quartz reactor and pretreated at $200^{\circ} \mathrm{C}$ in He for $0.5 \mathrm{~h}$ to remove adsorbed hydrates and carbonates. After cooling to $60^{\circ} \mathrm{C}, \mathrm{NH}_{3}$ gas pulses were injected until a stable signal was obtained, and the sample then heated to $900^{\circ} \mathrm{C}$ under $\mathrm{He}$ at $10^{\circ} \mathrm{C}$ min $^{-1}$. Synchrotron radiation experiments were performed at BL14B2 of SPring- $8^{62}$ and BL14W1 of the SSRF light sources. Pt $\mathrm{L}_{\mathrm{III}}{ }^{-}$edge transmission X-ray absorption spectra were acquired on samples loaded into the $\mathrm{Al}_{2} \mathrm{O}_{3}$ tube, in addition to $\mathrm{Pt}$ foil and $\mathrm{PtO}_{2}$ powder references. Spectra were background subtracted, normalized, and fitted using the IFEFFIT software suite ${ }^{63}$. X-ray photoelectron spectra (XPS) were performed on a VG ESCALAB MK2 apparatus using $\mathrm{Al} \mathrm{K}_{\alpha}$ radiation $(1486.6 \mathrm{eV}$, $12.5 \mathrm{kV}, 250 \mathrm{~W}$ ) to obtain the binding energies and oxidation states of Pt. Binding energies are referenced to adventitious carbon at $284.8 \mathrm{eV}$. High-angle annular dark-field scanning transmission electron microscopy (HAADF-STEM) images were obtained on a JEOL JEM-2100F. Aberration-corrected HAADF-STEM images were obtained on a JEOL JEM-ARM200F equipped with a CEOS probe corrector. Samples were dispersed by ultrasonication in ethanol, and the resulting solution dropped on to carbon films supported on copper grids. In situ imaging was performed on a Titan Cubed Themis G2 300 microscope using a DENSsolutions Climate S3 and Gas flow and Heating System, which comprised a heated sample holder and gas delivery manifold. The sample was mounted in a $5 \mu \mathrm{m}$ gap between two $30 \mathrm{~nm}$ thick SiN windows. The oxygen purity used for the in situ calcination experiment was $99.999 \%$. Reported temperatures were based on the DENSsolutions calibration. Low energy ion scattering (LEIS) spectra were acquired on a Kratos AXIS Supra spectrometer using $1 \mathrm{keV} \mathrm{He}{ }^{+}$ions generated from a Minibeam 6 Gas Cluster Ion Source, at a scattering angle of $130^{\circ}$, and $320 \mathrm{eV}$ analyzer pass energy, averaged over a sample area of $500 \mu \mathrm{m}^{2}$.

Catalytic evaluation. $\mathrm{CH}_{4}$ oxidation was performed in a U-shaped quartz reactor using $20 \mathrm{mg}$ catalyst and a feed gas comprising $0.5 \mathrm{vol} \% \mathrm{CH}_{4}, 3 \mathrm{vol} \% \mathrm{O}_{2}$, and $97 \mathrm{vol} \% \mathrm{He}$ balance at $30 \mathrm{~mL} \mathrm{~min}^{-1}$. The effluent gas composition was analyzed by an on-line Agilent $6890 \mathrm{~A}$ gas chromatograph equipped with a TDX-01 column and a thermal conductivity detector. $\mathrm{CH}_{4}$ conversion was calculated based on the difference between inlet and outlet concentrations.

Turnover frequency (TOF) calculation. TOFs were calculated from specific activities measured at $700{ }^{\circ} \mathrm{C}$ and approximately $20 \% \mathrm{CH}_{4}$ iso-conversion for $17 \mathrm{mg}$ $1 \mathrm{Pt} / \mathrm{Fe}_{2} \mathrm{O}_{3}-\mathrm{NP}$ and $6 \mathrm{mg} 1 \mathrm{Pt} / \mathrm{Fe}_{2} \mathrm{O}_{3}-\mathrm{C} 700$ catalysts respectively. A common gas flow rate of $50 \mathrm{~mL} \mathrm{~min}^{-1}$ was used, resulting in a space velocity of $176,000 \mathrm{~mL} \mathrm{~h}^{-1} \mathrm{~g}_{\text {cat }}{ }^{-1}$ for $1 \mathrm{Pt} / \mathrm{Fe}_{2} \mathrm{O}_{3}-\mathrm{NP}$ and $500,000 \mathrm{~mL} \mathrm{~h}^{-1} \mathrm{~g}_{\text {cat }}{ }^{-1}$ for $1 \mathrm{Pt} / \mathrm{Fe}_{2} \mathrm{O}_{3}-\mathrm{C} 700$. The Pt dispersion of $1 \mathrm{Pt} / \mathrm{Fe}_{2} \mathrm{O}_{3}$-NP was calculated according to the following relationship between the dispersion (D) and particle radius (r): $\mathrm{D} / \%=100^{*} 5.6 / \mathrm{r}_{\mathrm{Pt}}$. The average particle radius of $1 \mathrm{Pt} / \mathrm{Fe}_{2} \mathrm{O}_{3}-\mathrm{NP}$ was $15 \AA$ (Fig. 4c), corresponding to a dispersion of $30 \%$, while that for $1 \mathrm{Pt} / \mathrm{Fe}_{2} \mathrm{O}_{3}-\mathrm{C} 700$ was $100 \%$. TOFs were calculated by normalizing specific activities to the product of the dispersion and total $\mathrm{Pt}_{\text {mols }}$ (identical for both catalysts).

DFT parameters. All DFT $+\mathrm{U}$ calculations were performed using spin-polarized density functional theory (DFT) with the generalized gradient approximation (GGA) and Perdew-Burke-Ernzerhof (PBE) exchange-correlation functional as implemented in VASP5.3.5 $5^{64-66}$. The U-J value of $3.0 \mathrm{eV}$ was used to describe the strong correlation of the localized Fe $3 \mathrm{~d}$ states $3,67,68$. Valence states of all atoms were expanded in a plane wave basis set with a cutoff energy of $400 \mathrm{eV}$, and a Monkhorst-Pack mesh of $3 \times 3 \times 1 \mathrm{k}$ points was used for Brillouin Zone integration. Atomic positions were optimized by the conjugate gradient algorithm until forces were $<0.02 \mathrm{eV} / \AA$. Free energy changes were calculated from zero-point energies, enthalpies, and entropies of gas $\mathrm{Pt}$ single atom and $\mathrm{PtO}_{2}$ species corrected at 600,700 and $800^{\circ} \mathrm{C}$, respectively as summarized in Supplementary Table 3.

Computational models. A Pt $(221)-\mathrm{p}(3 \times 1)$ surface slab was used to model the step and edge of Pt NPs (coordination number $=7$ for atoms at edges). We applied periodic models of surface slabs with five atomic layers, with the bottom two layers frozen and the remaining layers allowed to relax. The (0001) surfaces of $\alpha-\mathrm{Fe}_{2} \mathrm{O}_{3}-\mathrm{p}$ $(2 \times 2)$ were also represented by a periodic slab model. Antiferromagnetic properties of $\alpha-\mathrm{Fe}_{2} \mathrm{O}_{3}$ were represented by a $(+--+)$ magnetic configuration, which was previously proven to be most energetically favorable for $\alpha-\mathrm{Fe}_{2} \mathrm{O}_{3}{ }^{3}$. We chose slabs containing 9 layers of $\mathrm{Fe}$ atoms and 5 atomic layers of $\mathrm{O}$ to model the $\mathrm{O}$-terminated surface. The bottommost $\mathrm{Fe}-\mathrm{O}$ layers were frozen during geometry optimization. A $\theta-\mathrm{Al}_{2} \mathrm{O}_{3}(010)-\mathrm{p}(4 \times 2)$ surface slab was used to model the alumina substrate, consisting of six $\mathrm{O}-\mathrm{Al}$ layers, wherein the bottom two $\mathrm{O}-\mathrm{Al}$ layers were frozen while the remaining layers were allowed to $\operatorname{relax}^{69,70}$. The IDIPOL tag was set to 3 to switch on dipole corrections to the total energy along the z-direction. All supercell slabs were periodically repeated with a $15 \AA$ vacuum layer between surfaces in the direction of the surface normal.

Theoretical maximum loading of dispersed $\mathrm{Pt}$ atoms over $\mathrm{Fe}_{2} \mathrm{O}_{3}$ support. The BET surface area of $\mathrm{Fe}_{2} \mathrm{O}_{3}$ was $5-10 \mathrm{~m}^{2} \mathrm{~g}^{-1}$, hence $1 \mathrm{~g}$ of $\mathrm{Fe}_{2} \mathrm{O}_{3}$ provides $\sim 5-10 \mathrm{~m}^{2}$ of surface (S). Our DFT calculation model indicates that the maximum density of atomically dispersed $\mathrm{Pt}(\mathrm{D})$ is 4.5 atom nm $\mathrm{nm}^{-2}$. The total number of isolated $\mathrm{Pt}$ atoms $(\mathrm{N})$ that could be achieved for $1 \mathrm{~g}$ of $\mathrm{Pt} / \mathrm{Fe}_{2} \mathrm{O}_{3}$ is therefore predicted to be $N=D \times S$. Since the mass of $\mathrm{Pt}(\mathrm{m})$ equals $\mathrm{N} / \mathrm{N}_{\mathrm{A}} \times \mathrm{M}$, where $\mathrm{N}_{\mathrm{A}}$ is Avogadro's constant $\left(6.02 \times 10^{23} \mathrm{~mol}^{-1}\right)$, and $\mathrm{M}$ is the molar mass of Pt $\left(195 \mathrm{~g} \mathrm{~mol}^{-1}\right)$, the theoretical maximum loading of isolated $\mathrm{Pt}$ atoms that could be dispersed over $1 \mathrm{~g}$ of $\mathrm{Fe}_{2} \mathrm{O}_{3}$ is $\mathrm{m}(\mathrm{g}) / 1(\mathrm{~g}) \times 100 \%=\left(D \times \mathrm{S} / \mathrm{N}_{\mathrm{A}}\right) \times \mathrm{M} \times 100 \%=1.5 \mathrm{wt} \%$.

\section{Data availability}

The data that support the plots within this paper and other findings of this study are available from the corresponding authors upon reasonable request.

Received: 2 August 2018 Accepted: 6 December 2018

Published online: 16 January 2019 


\section{References}

1. Ertl, G., Knözinger, H., Schüth, F. \& Weitkamp, J. Handbook of Heterogeneous Catalysis. 2nd edn, Vol. 1 (Wiley-VCH Verlag GmbH\& Co. KGaA, Weinheim, 2008).

2. Liu, L. \& Corma, A. Metal catalysts for heterogeneous catalysis: from single atoms to nanoclusters and nanoparticles. Chem. Rev. 118, 4981-5079 (2018).

3. Qiao, B. et al. Single-atom catalysis of $\mathrm{CO}$ oxidation using $\mathrm{Pt}_{1} / \mathrm{FeO}_{\mathrm{x}}$. Nat Chem. 3, 634-641 (2011)

4. Yang, X.-F. et al. Single-atom catalysts: a new frontier in heterogeneous catalysis. Acc. Chem. Res. 46, 1740-1748 (2013).

5. Flytzani-Stephanopoulos, M. \& Gates, B. C. Atomically dispersed supported metal catalysts. Annu. Rev. Chem. Biomol. Eng. 3, 545-574 (2012).

6. Mooiman, M. B., Sole, K. C., Dinham, N. Metal Sustainability (Wiley, Chichester, West Sussex, 2016)

7. Zhang, X. et al. C-C Coupling on single-atom-based heterogeneous catalyst. J. Am. Chem. Soc. 140, 954-962 (2018).

8. Zhao, P. et al. Entrapped single tungstate site in zeolite for cooperative catalysis of olefin metathesis with Bronsted acid site. J. Am. Chem. Soc. 140, 6661-6667 (2018).

9. Bruix, A. et al. Maximum noble-metal efficiency in catalytic materials: atomically dispersed surface platinum. Angew. Chem. Int. Ed. 53, 10525-10530 (2014).

10. Fei, H. et al. General synthesis and definitive structural identification of $\mathrm{MN}_{4} \mathrm{C}_{4}$ single-atom catalysts with tunable electrocatalytic activities. Nat. Catal. 1, 63-72 (2018).

11. Malta, G. et al. Identification of single-site gold catalysis in acetylene hydrochlorination. Science 355, 1399-1403 (2017).

12. Gao, J. et al. Tuning chemical bonding of $\mathrm{MnO}_{2}$ through transition-metal doping for enhanced CO oxidation. J. Catal. 341, 82-90 (2016).

13. Liu, G. et al. $\mathrm{MoS}_{2}$ monolayer catalyst doped with isolated Co atoms for the hydrodeoxygenation reaction. Nat. Chem. 9, 810-816 (2017).

14. $\mathrm{Li}, \mathrm{T}$. et al. Maximizing the number of interfacial sites in single-atom catalysts for the highly selective, solvent-free oxidation of primary alcohols. Angew. Chem. Int. Ed. 57, 7795-7799 (2018).

15. $\mathrm{Li}, \mathrm{H}$. et al. Synergetic interaction between neighbouring platinum monomers in $\mathrm{CO}_{2}$ hydrogenation. Nat. Nanotechnol. 13, 411-417 (2018).

16. Novotny, Z. et al. Ordered array of single adatoms with remarkable thermal stability: $\mathrm{Au} / \mathrm{Fe}_{3} \mathrm{O}_{4}(001)$. Phys. Rev. Lett. 108, 216103 (2012).

17. Upham, D. C. et al. Catalytic molten metals for the direct conversion of methane to hydrogen and separable carbon. Science 358, 917-921 (2017)

18. Marcinkowski, M. D. et al. Pt/Cu single-atom alloys as coke-resistant catalysts for efficient C-H activation. Nat. Chem. 10, 325-332 (2018).

19. Liu, P. et al. Photochemical route for synthesizing atomically dispersed palladium catalysts. Science 352, 797-800 (2016).

20. Chen, Z. et al. A heterogeneous single-atom palladium catalyst surpassing homogeneous systems for Suzuki coupling. Nat. Nanotechnol. 13, 702-707 (2018).

21. Shan, J., Li, M., Allard, L. F., Lee, S. \& Flytzani-Stephanopoulos, M. Mild oxidation of methane to methanol or acetic acid on supported isolated rhodium catalysts. Nature 551, 605-608 (2017).

22. Cui, X. et al. Synthesis of single atom based heterogeneous platinum catalysts: high selectivity and activity for hydrosilylation reactions. ACS Cent. Sci. 3, 580-585 (2017).

23. Yang, B., Burch, R., Hardacre, C., Headdock, G. \& Hu, P. Origin of the increase of activity and selectivity of nickel doped by $\mathrm{Au}, \mathrm{Ag}$, and $\mathrm{Cu}$ for acetylene hydrogenation. ACS Catal. 2, 1027-1032 (2012).

24. Qiao, B. et al. Highly efficient catalysis of preferential oxidation of $\mathrm{CO}$ in $\mathrm{H}_{2}$ rich stream by gold single-atom catalysts. ACS Catal. 5, 6249-6254 (2015).

25. Kwak, J. H. et al. Coordinatively unsaturated $\mathrm{Al}^{3+}$ centers as binding sites for active catalyst phases of platinum on $\gamma-\mathrm{Al}_{2} \mathrm{O}_{3}$. Science 325, 1670-1673 (2009).

26. Wan, J. et al. Defect effects on $\mathrm{TiO}_{2}$ nanosheets: stabilizing single atomic site $\mathrm{Au}$ and promoting catalytic properties. Adv. Mater. 30, 1705369 (2018).

27. Zhang, J. et al. Cation vacancy stabilization of single-atomic-site $\mathrm{Pt}_{1} / \mathrm{Ni}(\mathrm{OH})_{\mathrm{x}}$ catalyst for diboration of alkynes and alkenes. Nat. Commun. 9, 1002 (2018).

28. Wei, S. et al. Direct observation of noble metal nanoparticles transforming to thermally stable single atoms. Nat. Nanotechnol. 13, 856-861 (2018).

29. Fu, Q., Saltsburg, H. \& Flytzani-Stephanopoulos, M. Active nonmetallic Au and Pt species on ceria-based water-gas shift catalysts. Science 301, 935-938 (2003).

30. Fu, Q., Deng, W., Saltsburg, H. \& Flytzani-Stephanopoulos, M. Activity and stability of low-content gold-cerium oxide catalysts for the water-gas shift reaction. Appl. Catal., B 56, 57-68 (2005).

31. Hackett, S. F. J. et al. High-activity, single-site mesoporous $\mathrm{Pd} / \mathrm{Al}_{2} \mathrm{O}_{3}$ catalysts for selective aerobic oxidation of allylic alcohols. Angew. Chem., Int. Ed. 46, 8593-8596 (2007).

32. Sun, $\mathrm{S}$. et al. Single-atom catalysis using $\mathrm{Pt} / \mathrm{graphene}$ achieved through atomic layer deposition. Sci. Rep. 3, 1775 (2013).
33. Zhang, S. et al. Catalysis on singly dispersed bimetallic sites. Nat. Commun. 6, 7938 (2015)

34. Gates, B. C., Flytzani-Stephanopoulos, M., Dixon, D. A. \& Katz, A. Atomically dispersed supported metal catalysts: perspectives and suggestions for future research. Catal. Sci. Technol. 7, 4259-4275 (2017).

35. Liu, J. Catalysis by supported single metal atoms. ACS Catal. 7, 34-59 (2016).

36. Henrich, V. E. \& Cox, P. A. The surface Science of Metal Oxides. (Cambridge University Press, Cambridge, 1994).

37. DeRita, L. et al. Catalyst architecture for stable single atom dispersion enables site-specific spectroscopic and reactivity measurements of $\mathrm{CO}$ adsorbed to $\mathrm{Pt}$ atoms, oxidized Pt clusters, and metallic Pt clusters on $\mathrm{TiO}_{2}$. J. Am. Chem. Soc 139, 14150-14165 (2017)

38. $\mathrm{Li}, \mathrm{W}$. Z. et al. Stable platinum nanoparticles on specific $\mathrm{MgAl}_{2} \mathrm{O}_{4}$ spinel facets at high temperatures in oxidizing atmospheres. Nat. Commun. 4, 2481 (2013)

39. Bartholomew, C. H. Mechanisms of catalyst deactivation. Appl. Catal., A 212, 17-60 (2001)

40. Alcock, C. B. \& Hooper, G. W. Thermodynamics of the gaseous oxides of the platinum-group metals. Proc. R. Soc. Lond. Ser. A 254, 551-561 (1960).

41. Carrillo, C. et al. Trapping of mobile Pt species by PdO nanoparticles under oxidizing conditions. J. Phys. Chem. Lett. 5, 2089-2093 (2014)

42. Ganzler, A. M. et al. Tuning the structure of platinum particles on ceria in situ for enhancing the catalytic performance of exhaust gas catalysts. Angew. Chem. Int. Ed. 56, 13078-13082 (2017).

43. Jones, J. et al. Thermally stable single-atom platinum-on-ceria catalysts via atom trapping. Science 353, 150-154 (2016).

44. Moliner, M. et al. Reversible transformation of Pt nanoparticles into single atoms inside high-silica chabazite zeolite. J. Am. Chem. Soc. 138, 15743-15750 (2016).

45. Xiong, H. et al. Thermally stable and regenerable platinum-tin clusters for propane dehydrogenation prepared by atom trapping on ceria. Angew. Chem. Int. Ed. 56, 8986-8991 (2017).

46. Xie, P. et al. Nanoceria-supported single-atom platinum catalysts for direct methane conversion. ACS Catal. 8, 4044-4048 (2018).

47. Nie, L. et al. Activation of surface lattice oxygen in single-atom $\mathrm{Pt} / \mathrm{CeO}_{2}$ for low-temperature CO oxidation. Science 358, 1419-1423 (2017).

48. Liu, X. et al. Strong metal-support interactions between gold nanoparticles and $\mathrm{ZnO}$ nanorods in CO oxidation. J. Am. Chem. Soc. 134, 10251-10258 (2012).

49. Qiao, B. et al. Ultrastable single-atom gold catalysts with strong covalent metal-support interaction (CMSI). Nano Res. 8, 2913-2924 (2015).

50. Liu, J.-C., Tang, Y., Wang, Y.-G., Zhang, T. \& Li, J. Theoretical understanding of the stability of single-atom catalysts. Natl. Sci. Rev. 5, 638-641 (2018).

51. Liu, L. et al. Evolution and stabilization of subnanometric metal species in confined space by in situ TEM. Nat. Commun. 9, 574 (2018).

52. Ning, J. et al. Facile synthesis of magnetic metal ( $\mathrm{Mn}, \mathrm{Fe}, \mathrm{Co}$, and $\mathrm{Ni}$ ) oxides nanocrystals via a cation-exchange reaction. Nanoscale 3, 741-745 (2011).

53. Sytnyk, M. et al. Tuning the magnetic properties of metal oxide nanocrystal heterostructures by cation exchange. Nano. Lett. 13, 586-593 (2013).

54. Hansen, T. W., DeLaRiva, A. T., Challa, S. R. \& Datye, A. K. Sintering of catalytic nanoparticles: particle migration or ostwald ripening? Acc. Chem. Res. 46, 1720-1730 (2013).

55. Liu, J. C., Wang, Y. G. \& Li, J. Toward rational design of oxide-supported single-atom catalysts: atomic dispersion of gold on ceria. J. Am. Chem. Soc. 139, 6190-6199 (2017)

56. Urfels, L., Gélin, P., Primet, M. \& Tena, E. Complete oxidation of methane at low temperature over $\mathrm{Pt}$ catalysts supported on high surface area $\mathrm{SnO}_{2}$. Top. Catal. 30, 427-432 (2004)

57. Zhai, Y. et al. Alkali-stabilized $\mathrm{Pt}-\mathrm{OH}_{\mathrm{x}}$ species catalyze low-temperature water-gas shift reactions. Science 329, 1633-1636 (2010).

58. Yang, M. et al. Catalytically active $\mathrm{Au}-\mathrm{O}(\mathrm{OH})_{\mathrm{x}}$-species stabilized by alkali ions on zeolites and mesoporous oxides. Science 346, 1498-1501 (2014).

59. Yang, M. et al. A common single-site $\mathrm{Pt}(\mathrm{II})-\mathrm{O}(\mathrm{OH})_{\mathrm{x}}-$ species stabilized by sodium on "active" and "inert" supports catalyzes the water-gas shift reaction. J. Am. Chem. Soc. 137, 3470-3473 (2015).

60. Wei, H. et al. Remarkable effect of alkalis on the chemoselective hydrogenation of functionalized nitroarenes over high-loading $\mathrm{Pt} / \mathrm{FeO}_{\mathrm{x}}$ catalysts. Chem. Sci. 8, 5126-5131 (2017).

61. Wang, Y., Ren, J., Deng, K., Gui, L. \& Tang, Y. Preparation of tractable platinum, rhodium, and ruthenium nanoclusters with small particle size in organic media. Chem. Mater. 12, 1622-1627 (2000).

62. Cui, Y. T. et al. Development of in-situ cell for fluorescence-mode XAFS in BL14B2 of Spring-8. J. Phys. Conf. Ser. 502, 012039 (2014).

63. Ravel, B. \& Newville, M. ATHENA, ARTEMIS, HEPHAESTUS: data analysis for X-ray absorption spectroscopy using IFEFFIT. J. Synchrotron Radiat. 12, 537-541 (2005).

64. Kresse, G. \& Joubert, D. From ultrasoft pseudopotentials to the projector augmented-wave method. Phys. Rev. B: Condens. Matter Mater. Phys. 59, 1758-1775 (1999). 
65. Kresse, G. \& Furthmüller, J. Efficient iterative schemes for ab initio totalenergy calculations using a plane-wave basis set. Phys. Rev. B Condens. Matter Mater. Phys. 54, 11169-11186 (1996).

66. Perdew, J. P., Burke, K. \& Ernzerhof, M. Generalized gradient approximation made simple. Phys. Rev. Lett. 77, 3865-3868 (1996).

67. Anisimov, V. I., Aryasetiawan, F. \& Lichtenstein, A. First-principles calculations of the electronic structure and spectra of strongly correlated systems: the LDA $+U$ method. J. Phys. Condens. Matter 9, 767-808 (1997).

68. Dudarev, S., Botton, G., Savrasov, S., Humphreys, C. \& Sutton, A. Electronenergy-loss spectra and the structural stability of nickel oxide: An LSDA + U study. Phys. Rev. B: Condens. Matter Mater. Phys. 57, 1505-1509 (1998).

69. Moses-DeBusk, M. et al. CO oxidation on supported single Pt atoms: experimental and ab initio density functional studies of $\mathrm{CO}$ interaction with $\mathrm{Pt}$ atom on theta- $\mathrm{Al}_{2} \mathrm{O}_{3}(010)$ surface. J. Am. Chem. Soc. 135, 12634-12645 (2013).

70. Narula, C. K. \& Stocks, G. M. Ab Initio density functional calculations of adsorption of transition metal atoms on $\theta-\mathrm{Al}_{2} \mathrm{O}_{3}(010)$ surface. J. Phys. Chem. C. 116, 5628-5636 (2012).

\section{Acknowledgements}

This paper is dedicated to the 70th anniversary of the Dalian Institute of Chemical Physics, Chinese Academy of Sciences. This work was supported by National Natural Science Foundation of China (21606222, 21573232, 21776270, 21590792, 91645203, 51761165012), National Key Projects for Fundamental Research and Development of China (2016YFA0202801, 2017YFA0700104), Strategic Priority Research Program of the Chinese Academy of Sciences (XDB17020100), and DNL Cooperation Fund, CAS (DNL180403). The synchrotron radiation experiment was performed at the BL14B2 of SPring-8 with the approval of Japan Synchrotron Radiation Research Institute (Proposal No. 2011B1974), Japan, and the BL14W1 at the Shanghai Synchrotron Radiation Facility, Shanghai Institute of Applied Physics, China. We thank Kratos Analytical Ltd, Manchester for LEIS measurements. Financial grant from the China Postdoctoral Science Foundation (2017M621170). DICP Outstanding Postdoctoral Foundation (2017YB02), and dedicated funds for methanol conversion from DICP. J. Luo thanks National Program for Thousand Young Talents of China, Tianjin Municipal Science and Technology Commission (15JCYBJC52600). The authors thank Kai Wang, Mengke Ge and Xingang Hou for their assistance with in situ STEM measurements. The computational work was performed using supercomputers at Tsinghua National Laboratory for Information Science and Technology and Lvliang Tianhe-2 Supercomputing Center.

\section{Author contributions}

R.L. synthesized the catalyst and performed most of the reactions. S.M. performed the electron-microscopy characterization. W.X. and J.Luo performed the in situ electron microscopy. J-C.L. and J.Li did the theoretical calculations and analysis. Y-T.C., X.L. and Lei Li carried out the EXAFS experiment. Lin Li carried out the CO-DRIFT experiment. Y.C. and J.Lin provided reagent. T.L. and F.C. performed some experiments. A.F.L. provided the LEIS data and edited the manuscript. R.L. and B.Q. wrote the manuscript. A-Q.W. and X.W. revised the paper. B.Q. and T.Z. designed the study and supervised the project.

\section{Additional information}

Supplementary Information accompanies this paper at https://doi.org/10.1038/s41467018-08136-3.

Competing interests: The authors declare no competing interests.

Reprints and permission information is available online at http://npg.nature.com/ reprintsandpermissions/

Journal peer review information: Nature Communications thanks the anonymous reviewers for their contribution to the peer review of this work. Peer reviewer reports are available.

Publisher's note: Springer Nature remains neutral with regard to jurisdictional claims in published maps and institutional affiliations.

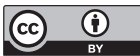

Open Access This article is licensed under a Creative Commons Attribution 4.0 International License, which permits use, sharing, adaptation, distribution and reproduction in any medium or format, as long as you give appropriate credit to the original author(s) and the source, provide a link to the Creative Commons license, and indicate if changes were made. The images or other third party material in this article are included in the article's Creative Commons license, unless indicated otherwise in a credit line to the material. If material is not included in the article's Creative Commons license and your intended use is not permitted by statutory regulation or exceeds the permitted use, you will need to obtain permission directly from the copyright holder. To view a copy of this license, visit http://creativecommons.org/ licenses/by/4.0/.

(C) The Author(s) 2019 